Portland State University

PDXScholar

Dissertations and Theses

Dissertations and Theses

Spring 1-1-2012

\title{
The Role of Compliment Topics in Compliment Response
}

Hiroko Katsuta

Portland State University

Follow this and additional works at: https://pdxscholar.library.pdx.edu/open_access_etds

Part of the Discourse and Text Linguistics Commons, East Asian Languages and Societies Commons, and the Morphology Commons

Let us know how access to this document benefits you.

\section{Recommended Citation}

Katsuta, Hiroko, "The Role of Compliment Topics in Compliment Response" (2012). Dissertations and Theses. Paper 466.

https://doi.org/10.15760/etd.466

This Thesis is brought to you for free and open access. It has been accepted for inclusion in Dissertations and Theses by an authorized administrator of PDXScholar. Please contact us if we can make this document more accessible: pdxscholar@pdx.edu. 
The Role of Compliment Topics in Compliment Response

by

Hiroko Katsuta

A thesis submitted in partial fulfillment of the requirements for the degree of

\author{
Master of Arts \\ in \\ Japanese
}

Thesis Committee:

Suwako Watanabe, Chair

Patricia J. Wetzel

Laurence R. Kominz

Portland State University

2012 


\begin{abstract}
This study examines the role of compliment topic by analyzing compliment responses by Japanese and American college students. Compliment responses can be seen as solutions for maintaining a balance between (1) a preference to avoid self-praise and (2) a preference to accept or agree with the compliment (Pomerantz 1978). Building on studies showing that response strategies can be influenced by compliment content and context, the study analyzed responses to compliments on ability, achievement, belongings, appearance, and personal characteristics by determining the subjects' choice of response strategy—categorized as acceptance, avoidance, or rejection—for each compliment topic.

Compliment responses were elicited in a recorded, free-flowing conversation by the researcher or the English speaking research assistant's issuing of compliments on traits of the participants based on information collected prior to the conversation by e-mail. Compliments were subtly dispersed throughout the conversation. Each compliment response was coded according to whether the overall response accepted, avoided, or rejected the credit attributed by the compliment, while the component parts of each response were coded by semantic formulas.

The American group accepted compliments more often than the Japanese group and the Japanese group avoided and rejected compliments more often than the English group. But, contrary to a commonly held belief, the Japanese speakers did not overwhelmingly reject compliments, and instead used all three response types with a substantial frequency. The American participants overwhelmingly accepted compliments and almost never rejected compliments, but avoidance strategies were also commonly
\end{abstract}


observed and should not be overlooked in the discussion of American English compliment response patterns.

Furthermore, the study found relations between the content and structure of compliment responses and the type of compliment topic. Overall response strategies varied relative to compliment topic, as compliments on personal appearance were overwhelmingly rejected or avoided by both groups while those on belongings were largely accepted by both groups. Some response structures were also unique to a type of compliment topic, including the use of "wa" as a limit on the credit accepted in response to compliments on achievements or the use of "“a' + gratitude" as a means of demonstrating modesty in response to compliments on belongings. 


\section{DEDICATION}

To my mom, Midori Ikeda, for her endless love and support. 


\section{ACKNOWLEDGEMENTS}

I would like to express my deep appreciation to the following people:

My thesis advisor, Dr. Suwako Watanabe, for selflessly providing so much of her time, knowledge, and warm support. She was truly willing to offer her assistance anytime I needed it. I am amazed by her boundless energy for developing her knowledge and for her willingness to impart it to her students. I could not have completed this project without her guidance, kindness, and encouragement. Dr. Patricia J. Wetzel, who gave me the opportunity to teach and study Japanese at PSU. It has been an inspirational and exciting experience. Thank you for patiently pushing me through the basics of sociolinguistics, for challenging me, for helping me to develop my thought processes as I (endlessly) searched for a thesis topic, and for being an all-around source of energy and inspiration. I was always cheered up after visiting her office and her scholarship taught me that linguistics can be intellectually rigorous but also sometimes fun. Dr. Laurence Kominz for his kind words and care throughout the thesis writing process and throughout my time at PSU. His thoughtful comments and insights were invaluable in revising this thesis and helped me to understand it in new ways. Dr. Emiko Konomi for being a model of how to be a tremendous teacher and scholar. Thomas Mason Jr. for allowing me to participate in the ALLEX program and for training me as a Japanese teaching assistant. Jessica Kindler for taking so much time out of her busy schedule to help me gather the English data. Ryan Delatorre for helping me so patiently and kindly with my writing, his thoughtful advice through the whole process, and for his warm support. Larry Crawshaw and Douglas Walker for their very thoughtful and very careful feedback to my earlier 
drafts. Their friendship was invaluable and helped me to get through some of the tougher times. Miki Murakami and Kanako Yao for being wonderful friends, for their encouragement and support, and for being my PSU thesis fellow-travelers. Amanda Gerke and Kathleen Orcutt for their caring friendship. And finally, all the participants in this study for devoting their precious time, because none of this was possible without them. 


\section{TABLE OF CONTENTS}

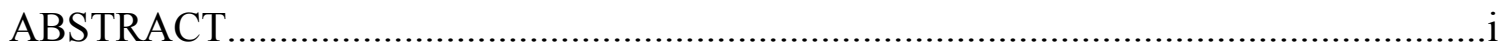

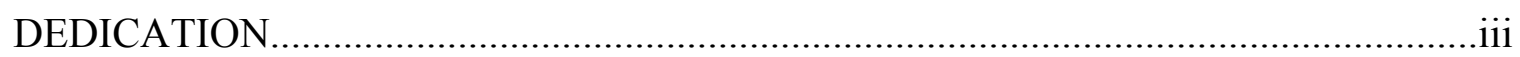

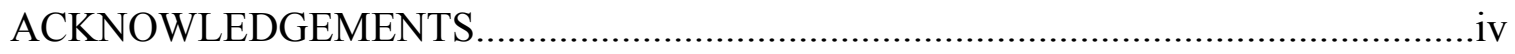

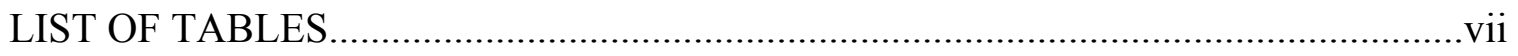

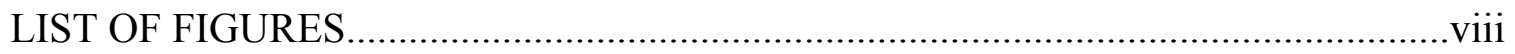

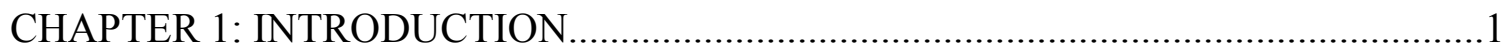

CHAPTER 2: LITERATURE REVIEW ...............................................................4

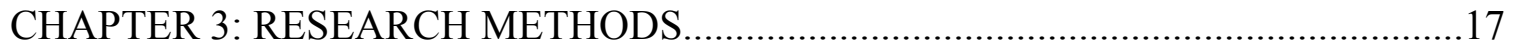

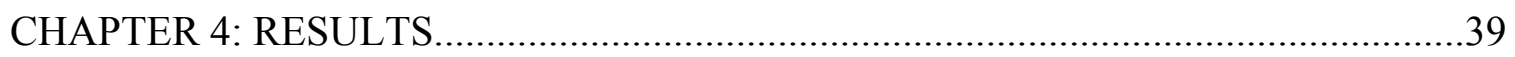

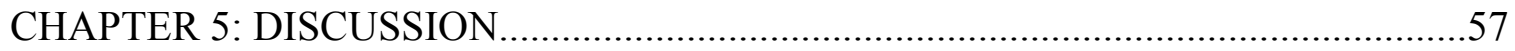

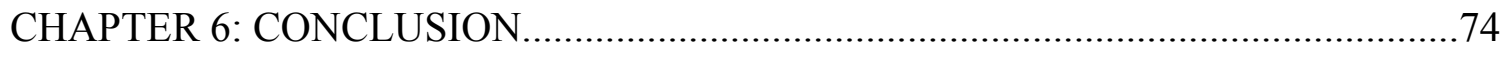

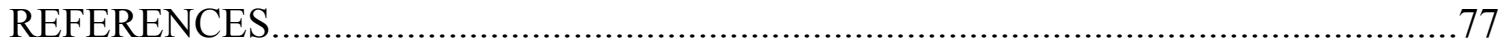

APPENDICES

A. ENGLISH INFORMED CONSENT FORM........................................... 80

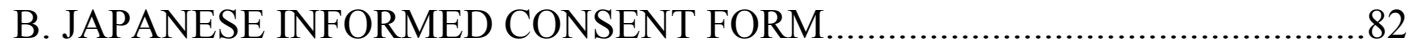

C. ENGLISH BIOGRAPHIC INFORMATION QUESTIONNAIRE....................83

D. JAPANESE BIOGRAPHIC INFORMATION QUESTIONNAIRE.................84

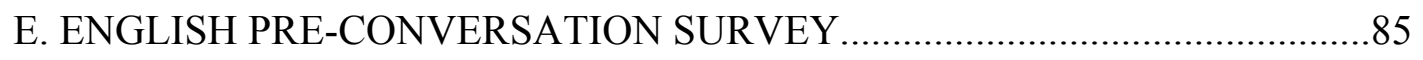

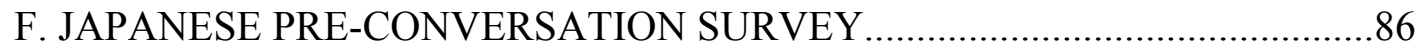

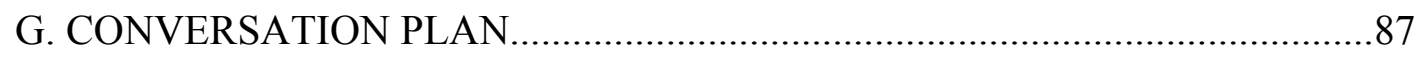




\section{LIST OF TABLES}

TABLE 1

Compliment topic categories.

TABLE 2

Holmes' compliment response categorization.....................................................................

TABLE 3

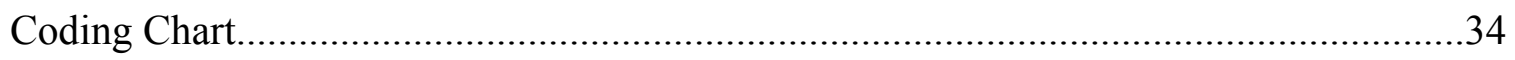

TABLE 4

Japanese and English overall results.............................................................................

TABLE 5

Japanese and English compliment topic results...............................................................43

TABLE 6

Japanese and English acceptance responses..................................................................45

TABLE 7

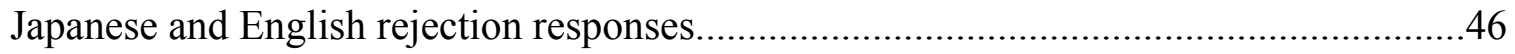

TABLE 8

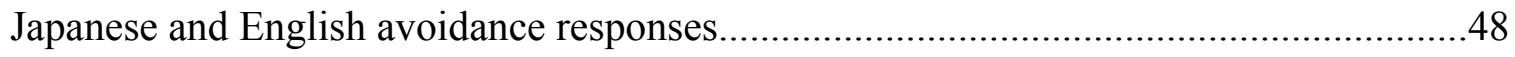

TABLE 9

Agreement semantic formula usage rate...................................................................5

TABLE 10

Gratitude and $\mathrm{Oh} / A \mathrm{SF}$ usage rate in response to compliments about belongings.............56 


\section{LIST OF FIGURES}

\section{FIGURE 1}

Japanese overall results.

FIGURE 2

English overall results.

FIGURE 3

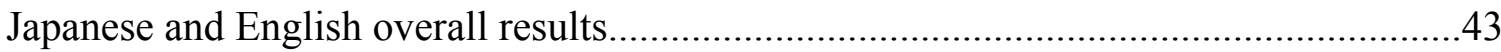

FIGURE 4

English compliment topic results 44,65

FIGURE 5

Japanese compliment topic results. $.44,65$

FIGURE 6

Acceptance rates for each topic in the JPN and ENG groups 45,66

FIGURE 7

Rejection rates for each topic in the JPN and ENG groups 47,66

FIGURE 8

Avoidance rates for each topic in the JPN and ENG groups. $.48,67$

FIGURE 9

English and Japanese ability topic category results

FIGURE 10

Japanese and English overall semantic formula results

FIGURE 11

Occurrence of semantic formulas in acceptance responses .52

FIGURE 12

Agreement SF usage rate. .55 


\section{CHAPTER 1: INTRODUCTION}

Pomerantz (1978) proposed that compliments present a quandary for those who receive them. When responding to a compliment, the compliment recipient is confronted with two conflicting preferences. On one hand, people are inclined to (a) avoid self-praise, on the other hand they are inclined to (b) accept or agree with the compliment. Acceptance of or agreement with a compliment ratifies praise of the complimentee and implicitly equates to an act of self-praise. Conversely, the avoidance of self-praise requires that the complimentee reject (and therefore contradict the complimenter) or at least refuse to accept a compliment.

Thus, an unequivocal expression of acceptance or agreement will tend to conflict with the preference to avoid self-praise, while an unequivocal expression of self-praise avoidance will similarly tend to conflict with the preference to accept or agree. As a result, compliment responses tend to fall somewhere in between the two extremes of unequivocal acceptance/agreement and unequivocal self-praise avoidance. Pomerantz concluded that compliment responses can be seen as solutions or resolutions for maintaining a balance between complete avoidance of self-praise and complete acceptance or agreement.

Studies investigating compliment response strategies in Japanese have found that content and context influence the extent to which a respondent has a preference for avoiding self-praise (i.e., not to agree with a compliment) (Fukushima 1993; Baba 1999). This study extends the investigation of the impact of content by exploring the relationship 
between compliment topics and compliment response. In contrast with previous studies, this study utilizes a research design in which compliment topic is highlighted as a factor in relation to compliment response. An analysis of responses to compliments on ability, achievements, appearance, personality, and belongings allows for a nuanced examination of the relationship between variations in compliment content and compliment response strategies used by Japanese and English native speakers.

My hypothesis is that compliment topic is one factor that plays a role in determining how we respond to a compliment. I hypothesize that certain compliment topics will increase or decrease a complimentee's preference for the avoidance of self-praise. I also hypothesize that response tendencies differ across cultures and that the compliment topic will affect response preferences differently in Japanese and Americans.

If, as Pomerantz theorizes, compliment responses strike a balance between self-praise avoidance and acceptance or agreement, an increased or decreased preference for self-praise avoidance should be reflected in the content of compliment responses. Topics that increase the preference to avoid self-praise should correspond to increased rejection of compliments. Similarly, topics that decrease the preference to avoid self-praise should correspond to increased acceptance of compliments.

Responses to compliments were elicited from native speakers of Japanese and American native speakers of English during a free-flowing conversation with a researcher or research assistant. The researcher or research assistant complimented the interviewees on a set of predetermined topics in order to allow comparison of effects between topics and between cultures. However, compliments were personalized to maintain authenticity. 
The subjects' responses to the compliments provided the target data. The data was grouped according to language group and compliment topic. The data was quantitatively and qualitatively compared as follows:

1. Total Japanese responses (responses to all topics) compared to total American responses (responses to all topics);

2. Responses for each topic as compared to the responses for each of the other topics within the same language group; and

3. Japanese responses for each topic as compared to American responses to the same topic.

The analysis compares the affect of each topic, both within and between language groups, in terms of whether the participants accepted, rejected, or avoided the compliment. A semantic formula analysis was also conducted to examine the response strategies employed. 


\section{CHAPTER 2: \\ LITERATURE REVIEW}

\subsection{Preference Systems Affecting the Speech Act of Compliment Response}

Pomerantz (1978) observed that compliment responses of American English speakers are largely influenced by two cultural preferences: to (a) avoid self-praise and (b) accept or agree with the compliment. These preferences, however, are in conflict, or at least inconsistent with each other. Acceptance of or agreement with a compliment ratifies praise of the complimentee and implicitly relates to an act of self-praise. Conversely, the avoidance of self-praise requires that the complimentee reject or at least refuse to accept a compliment.

Pomerantz concluded that, when engaging in compliment response, complimentees often seek a solution to, or resolution of, this conflict by striking a balance between complete avoidance of self-praise and complete acceptance or agreement. Specifically, she found that American English complimentees often express token acceptance or agreement with a compliment while at the same time scaling down or refocusing praise. Scaling down is achieved by utilizing a less positive evaluative descriptor than the compliment, by which the complimentee performs an evaluation shift in the form of a praise downgrade. Refocusing is a referent shift, in which the complimentee offers praise of someone or something other than the self. A referent shift can be accomplished by refocusing praise on an object or by returning the compliment to the complimenter. Thus, according to Pomerantz's findings, compliment responses in 
American English can be seen as utilizing varying strategies for reaching a compromise within a contradictory system of cultural constraints.

Leech's (1983) Maxims of Politeness provide another construct for analyzing compliment response. He proposed the following maxims.

(I) Tact Maxim

(a) Minimize cost to other [(b) Maximize benefit to other]

(II) Generosity Maxim

(a) Minimize benefit to self [(b) Maximize cost to self]

(III) Approbation Maxim

(a) Minimize dispraise of other [(b) Maximize praise of other]

(IV) Modesty Maxim

(a) Minimize praise of self [(b) Maximize dispraise of self]

(V) Agreement Maxim

(a) Minimize disagreement between self and other [(b) Maximize agreement between self and other]

(VI) Sympathy Maxim

(a) Minimize antipathy between self and other [(b) Maximize sympathy between self and other]

These principles include primary maxims along with weaker submaxims, which are indicated by brackets. The Agreement and Modesty Maxims come into conflict in the act of compliment response because the complimentee may seek to minimize self-praise by rejecting the compliment, but in the process can create disagreement with the complimenter, violating the Agreement Maxim. Or, the complimentee may seek to minimize disagreement with the complimenter by accepting the compliment but in the process engage in self-praise, which violates the Modesty Maxim. 
Leech notes that when two maxims come into conflict with each other the more "powerful" maxim takes priority. He also notes that the relative strength of maxims will vary between cultures, leading to differing resolutions in situations where maxims conflict. As a result, some of the variation in compliment response type between language and culture groups can be explained by differences in the relative strength of the Agreement and Modesty Maxims.

Studies investigating compliment response in Japanese indicate that the tendency to accept or agree with a compliment does not occur as often as it does in English. (Yokota, 1985; Daikuhara, 1986; Fukushima, 1993; Saito and Beecken, 1997; and Baba, 1999). These studies demonstrate that Japanese compliment response features a mixture of Accept/agreement, Avoidance, and Reject/denial responses. These studies also demonstrate a high degree of variability in the form of compliment response in Japanese. For example, acceptance/agreement response rates have been observed as low as 5\% (Daikuhara, 1986) (in response to compliments elicited in role-play scenarios) and as high as 68\% (Saito and Beecken, 1997) (in response to compliments from friends).

Whereas some of the variation in acceptance rates can be attributed to the data collection method, other factors are likely more important. Studies on Japanese compliment response have shown major alterations in response depending on differences in compliment content and context. Yokota (1985) studied compliment responses in Japanese and demonstrated significant differences between responses to compliments about family members and responses about self. Saito and Beecken (1997), who studied native Japanese speakers' responses to compliments, found that responses were 
significantly affected by a change in status of the complimenter. Fukushima (1993)

showed differences based on the formality of the situation, gender of the complimentee, and compliment topic. And Baba (1999) demonstrated an effect of the referent, but had mixed results with respect to compliment topic.

\subsection{Compliment Source and Referent as Variables Affecting Compliment Response}

\section{a. Yokota (1985): Compliment referent as a variable}

Yokota (1985) examined the referent(s) of a compliment as a variable influencing compliment response. Specifically, she studied situations in which compliments were made toward the listener-self as opposed to compliments about the listener's family members. 60 college students participated in a questionnaire survey called a Discourse Completion Task (DCT), in which they were asked to give written responses to comments given by a friend in ten hypothetical situations. Participants received five compliments referring to themselves and then five compliments referring to their family members. Responses were categorized as belonging to one of three groups - positive, avoidance, and negative.

Yokota's data showed that there were significant differences within Japanese participants between responses to compliments about family members and responses about self. For the American English group, positive, avoidance, and negative responses occurred at a similar rate as compliments referring to family members and compliments referring to self, but there was a marked difference among the group qualitatively. Specifically, compliment responses referring to family members often emphasized a positive evaluation while compliment responses referring to self almost never did so. 
Quantitative differences, on the other hand, were seen in the Japanese group, as there was a higher rate of positive responses referring to self and a higher rate of avoidance responses referring to family.

Overall, Yokota observed that $16 \%-26 \%$ of Japanese compliment responses were positive even though the majority of responses were avoidance $(54 \%-66 \%)$ or denial (18\%-20\%). Moreover, a major qualitative difference between the American and Japanese groups was that the American group added to or explained something about the compliment in more than half of the positive responses while the Japanese group most commonly changed the topic or reduced the compliment after a positive response.

\section{b. Saito and Beecken (1997): Social status of the complimenter as a variable}

While Yokota focused on the compliment referent, Saito and Beecken (1997) examined the social status of the complimenter. Their primary goal was to study the effects of pragmatic transfer (the transference of native language tendencies into a second language) by observing whether American learners of Japanese experience any difficulty in learning appropriate responses to compliments in Japanese, and if so, how the teaching of responses to compliments might be changed.

American learners of Japanese provided the experimental group, while native Japanese speakers and American speakers of English provided a normative baseline. A total of 30 college students participated in a closed role-play design. The students were asked to respond to comments given by a professor and by a friend in five hypothetical situations. Participants in all three groups received the same five compliments twice, once given by a professor and the second time by a friend. All of the utterances were 
audiotaped, transcribed, and analyzed with an Initial Sentence Analysis (an analysis focusing exclusively on the initial sentence of each compliment response) and Semantic Formula Analysis (an analysis of the order of speech act components in order to find patterns of utterance structures). Responses were categorized as positive, avoidance, or negative based upon the Initial Sentence Analysis formula.

The results of the Initial Sentence Analysis indicated that a majority of responses were positive across the three groups. The American speakers of English normative data suggested a dominant use of positive strategies that was more pronounced than those utilized by the other groups. Contrary to the common view that Japanese speakers respond negatively to compliments, the native Japanese speakers normative data suggested a mixture of positive, avoidance, and negative responses, although the native Japanese speakers as a group used avoidance more than the other groups. And finally, the American learners of Japanese data (performing in Japanese) suggested a mixture of positive, avoidance, and negative responses although they used more negative responses than the native Japanese speakers.

Saito and Beecken also found that the native Japanese speakers group was significantly influenced by a change in status of the complimenter. The Japanese native speakers gave a greater number of positive compliment responses in response to compliments from friends ( $68 \%$ as compared to $46 \%$ positive compliment responses from compliments from professors) and fewer negative compliment responses in response to compliments from friends ( $6 \%$ as compared to $24 \%$ from compliments from professors). Avoidance stayed relatively constant (26\% to compliments from friends, $30 \%$ to 
compliments from professors). The compliment responses of American English native speakers, on the other hand, were only slightly affected by the status of the complimenter. In contrast to the native Japanese speakers, the American group responded more positively to compliments from professors ( $98 \%$ as compared to $90 \%$ positive compliment responses from compliments from friends) and with less avoidance ( $2 \%$ as compared to $10 \%$ to compliments from friends). Negative responses were $0 \%$ in response to compliments from both professors and friends.

The Semantic Formula Analysis also revealed qualitative differences between the native English and native Japanese speakers. In response to a friend's compliment, the American learners of Japanese and American English native speakers used simple gratitude most often, but native Japanese speakers most frequently responded using agreement --> affirmative explanation strings. Moreover, most native Japanese speaker denials were followed by return, mitigation, or affirmative explanations, whereas a majority of American learners of Japanese negative responses were simple denials containing one sentence.

c. Fukushima (1993): Formality of the situation, gender of the complimentee, and compliment topic as variables.

Fukushima (1993) conducted a study focusing on the effect of formality, gender, and compliment topic. A total of 52 Japanese tourists from Japan participated in the study (26 female, 26 male). Participants were given a written situation and written partial dialogue and asked to respond orally, in a natural fashion, to the researcher. 
Fukushima categorized compliment topics into two groups, "internal stable uncontrollable" (ability, appearance) and "external unstable controllable" (work, belongings). Responses were categorized as either "denial” or "other."

Fukushima found that formal compliments were denied more often than informal compliments, that female complimentees denied compliments more often than male complimentees, and "internal stable uncontrollable" compliments were denied more than "external unstable controllable" compliments. Out of two sets of 208 elicited responses, "internal stable uncontrollable" compliments were denied 94 times $(45.2 \%$ of responses) while "external unstable controllable" compliments were denied 27 times (13.0\% of responses).

\section{d. Baba (1999): Referent and compliment topic as variables}

Baba (1999) investigated pragmatic transfer in American learners of Japanese in compliment response, focusing specifically on the effect of compliment referent as well as compliment topic. Baba grounded her analysis in Brown and Levinson's politeness theory. She argued that the more face threatening (the degree to which an act is in opposition to the wants or desires of the other) a compliment is the more likely it is that the compliment response will utilize Negative Politeness strategies (generally characterized as "respect behavior" or indications of modesty, typified by rejection/disagreement). She further argued that a compliment would be more face threatening if its topic were closely related to the identity of the "self" because acceptance of such compliments runs the risk of violating the social code against self-praise. 
Baba divided compliment topics into two categories in order to test her hypothesis; compliments on external characteristics and compliments on internal characteristics. Internal topics included compliments referring to (1) skill, (2) abilities, and (3) personal attributes. External topics included compliments referring to physically tangible things such as (1) physical attributes or (2) attire. The notable difference between Baba and Fukushima's categorization systems was that "appearance" was categorized by Fukushima as "internal stable uncontrollable" while Baba categorized "physical attributes" as an external topic. One may also note that "work," while categorized by Fukushima as “external unstable controllable," would have likely been categorized by Baba as an internal topic. Baba hypothesized that (1) internal compliments would be rejected/disagreed with more by both native American English speakers and native Japanese speakers because of the aversion to self-praise in both cultures; and (2) that Japanese native speakers would reject/disagree with internal compliments more than native American English speakers because of the greater Japanese cultural emphasis on modesty and thus a greater aversion to self-praise.

Baba employed a Labovian data collection technique in which natural data were collected in a controlled context. Data was collected from conversations involving four subject groups: American speakers of English, Japanese speakers of Japanese, Japanese learners of English, and American learners of Japanese. Sixty "discussion leaders" (12 for American speakers of English, 17 for Japanese speakers of Japanese, 14 for Japanese learners of English, and 17 for American learners of Japanese) were asked to bring one friend for a thirty-minute conversation at a coffee shop or other casual meeting place. The 
leaders were not specifically required to give compliments but, prior to the conversation and before the participants arrived, the researcher gave them "hints" that they should freely give compliments where they felt it would be natural to do so. The conversation was audio recorded while the researcher secretly watched the conversation from a distance. The audio recordings were then transcribed.

Compliment responses were categorized into one of four types: Positive Politeness, Negative Politeness, Off-the-Record, and Do-Not-Do-FTA. Generally, Positive Politeness compliment responses were those that indicated intent to create a feeling of "intimacy" between the complimenter and complimentee, including expressions of acceptance or agreement. The Negative Politeness category was characterized by a demonstration of "respect behavior" or an indication of intent to show modesty, including expressions of rejection or disagreement. Off-the-Record compliment responses were characterized by an indirect usage of language in which the complimentee avoided making either a Positive Politeness or Negative Politeness response. And finally, the Do-Not-Do-FTA encompassed compliment responses in which the compliment response made no comment on the compliment.

With regard to the impact of compliment topic, Baba's study showed mixed results. Contrary to Baba's hypothesis, the Japanese speakers of Japanese group was more likely to use Positive Politeness in response to internal compliments and more likely to use Negative Politeness in response to external compliments. Moreover, while the American speakers of English group (as expected) was more likely to use Positive Politeness in response to external compliments, they were (unexpectedly) also more 
likely to use Negative Politeness in response to external compliments. Baba did note that the observed tendency of the Japanese speakers of Japanese to accept internal compliments only applied when family was the referent.

Baba's results with respect to target were more consistent with the predicted outcomes. All groups showed an increased tendency to use Positive Politeness in response to compliments referring to family members as opposed to compliments referring to the complimentee. Meanwhile, the Japanese speakers of Japanese group used more Negative Politeness than the other groups when the compliment referred to family members.

\subsection{Limitations of Previous Studies in the Examination of Compliment Topic}

Fukushima (1993) and Baba (1999) both examined compliment topic and used a categorization scheme that grouped compliments as internal or external based on the content of the compliment. However, they disagreed as to the definition and characterization of compliments related to appearance/physical attributes. Fukushima categorized compliments about appearance as internal while Baba categorized compliments about physical attributes as external. Fukushima and Baba also employed different data collection methodologies, with Fukushima employing role-play scenarios and Baba studying natural data in a controlled scenario. Thus, it is difficult to compare Fukushima and Baba's results on compliment topic and hard to reach definitive conclusions about the relationship between compliment topic and compliment response. While Fukushima found that "internal stable uncontrollable" compliments were rejected or disagreed with more frequently by his Japanese study group, Baba's results showed a 
higher than expected rate of rejection/disagreement of "external" compliments in both her Japanese and American study groups.

I propose that Baba's data collection methods were sound but that a more specific comparison of individual topics as opposed to a comparison of categories of topics would have provided a more detailed, representative, and explanatory set of results. A researcher's categorization of data is imposed on data rather than resulting from an analysis of data, and thus can impact results (Golato, 2005). The disagreement between Baba and Fukushima over the correct categorization of "appearance" demonstrates this point. Compliments that would have qualified as relating to "internal" content in Fukushima's study would have been categorized as "external” in Baba's. In other words, each study's method of categorization directly affected the quantitative results.

Moreover, even if it is true that topics related to the identity of self are more face threatening and that "internal" topics are generally more related to the identity of self than "external" topics, this does not mean that all "internal" topics show an increased relationship to the identity of self than do "external" topics. It is, for example, at least controversial to say that one's model train hobby is more related to one's identity of self than the appearance of one's face merely because the model train hobby is an "internal" trait while one's face is an "external" one. Such broad categorizations are particularly troublesome when making intercultural comparisons, where the relationship between a topic and the concept of self may vary in each culture. 


\subsection{Research Questions and Hypothesis}

Research Question 1: What response strategies are used by American and Japanese college students when responding to a compliment in a casual conversation?

Hypothesis 1: English native speakers will tend to accept more compliments than native Japanese speakers.

Hypothesis 2: Japanese native speakers will tend to avoid and reject more compliments than native English speakers.

Research Question 2: What similarities and differences are observed between the two groups in the content and sequencing of compliment responses?

Hypothesis 3: When accepting compliments, Japanese native speakers will tend to mitigate acceptance while English native speakers will tend to express agreement or gratitude without mitigation.

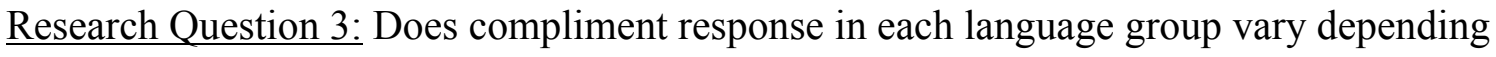
on the topic of the compliment?

Hypothesis 4: Compliment response types will vary according to compliment topic. 


\section{CHAPTER 3: \\ RESEARCH METHODS}

\subsection{Research Design of this Study}

This study uses quantitative and qualitative methods focusing on the speech act of compliment response, and in particular variations in compliment response that correspond to variations in compliment topic. The research methodology employed was based, in part, on studies by Baba (1999) and Fukushima (1993), although several new practices were developed by the researcher.

In this study, compliment responses were elicited in a free-flowing conversation by the researcher's or a research assistant's issuing compliments on a participant's various traits. Compliment content was drawn from information that had been submitted prior to the conversation. Compliments were subtly dispersed throughout the conversation and made on a set of target compliment topics that included the participant's personal appearance, characteristics, abilities, achievements, and clothing/belongings.

\subsection{Pilot Studies}

The main purpose of the pilot studies was to confirm whether or not the instruments, mainly the pre-conversation survey and the conversation setting, were appropriate to achieve the goals of the study. The results of the pilot studies were then used to improve the data collection procedure.

Two native speakers of Japanese who grew up in Japan participated in the first pilot study. They were graduate students of a university on the west coast of North America. This first pilot study did not employ a pre-conversation survey. Instead, the 
researcher set conversation topics ("Discuss a recent large purchase" and "Discuss a traveling experience") and asked the two participants to discuss them. The conversation topics were designed to facilitate the giving of compliments. The conversation was video-taped.

Contrary to the expectation that the topics would trigger compliments, very few compliments occurred. This meant that many conversations and many hours of recordings would be required in order to gather an adequate corpus. Even when compliments occurred, they did not represent an adequate range of target compliment topics. Since the focus of this study was on the relation between compliment response and compliment topics, it was decided to develop a procedure that ensured elicitation of responses on a sufficient range of topics, in a conversation that would be as natural as possible.

After the first study, the researcher developed a pre-conversation survey that covered a set of target compliment topics such as achievements, personal characteristics, hobbies, opinions, and abilities. The researcher also asked a friend or acquaintance of each participant to mention something they liked about the participant, which was then relayed to the participant during the conversation as a second-hand compliment. The researcher or a research assistant acted as a conversation leader and complimented on the topics drawn from the pre-conversation survey as well as physical features and objects such as their outfit and handwriting. This procedure was evaluated in a second pilot study. Two people participated in the second pilot study. The participants were again graduate 
students of a university on the west coast of North America who were native speakers of Japanese and had grown up in Japan.

The second pilot study was much more successful, but compliments on hobbies and opinions proved to be difficult to implement in the conversation. The primary difficulty was that positive attributions regarding hobby and opinion were generally not recognized as compliments, but instead seemed to be understood as comments regarding the specific hobby or opinion being discussed. Those topics were eliminated as targets for this study. It was also noted that compliments on the remaining topics would have to be given in such a way as to make clear that the credit was being attributed to the participant and not to the particular topic being discussed. Finally, the second pilot study provided valuable insight into the techniques a conversation leader could utilize in order to integrate compliments into the conversation in as natural a way as possible.

\subsection{Participants}

14 American native speakers of English and 14 native speakers of Japanese participated in this study. Of the English group, 2 were graduate students and 12 were undergraduate students of a university on the west coast of North America. They ranged in age from 18-31 years old. The Japanese group consisted of 14 undergraduate students of a Japanese university who had been studying abroad at a university on the west coast of North America for a period of 2 to 6 months. By limiting the study to exchange students who had been studying in the United States for less than 6 months, it was hoped that the data collected would resemble as closely as possible such data as would be 
collected from native Japanese speakers actually living in Japan. The Japanese participants ranged in age from $20-24$ years old.

One research assistant was recruited and trained to act as a conversation leader for the American group. The research assistant was a 27 year-old native speaker of English, who was a graduate student at a university on the west coast of North America.

The effect of gender is not a focus of this paper, and so differences in responses between males and females will be examined minimally. In order to minimize gender as a source of bias in the data and to obtain the strategies used by both genders, both the Japanese and American groups consisted of an equal gender ratio ( 7 males, 7 females). The researcher and research assistant were both female in order to minimize inconsistency in the comparison between the two language groups.

Participants were recruited through the use of posters, announcements, and personal communications. Research participants were told that the study concerned "student narratives" and did not know that compliment response was the focus of the study. An application for human subject research review was submitted and approved. The consent form is included in Appendix 1.

\subsection{Issues in Data Collection Methods}

The three goals of this study's research design were to: (1) elicit naturally occurring utterances within a managed context; (2) elicit discourse data allowing the researcher to analyze compliment response strategies in detail; and (3) elicit data enabling the researcher to examine the role of compliment topic in responses to compliments. Several data collection procedures were utilized in the previous studies on compliments 
and compliment responses, including questionnaires, discourse completion tasks (DCTs), role-plays, recall protocols, field observation, and recordings of naturally occurring talk-in-interaction. This study utilized recordings of naturally occurring talk-in-interaction for reasons highlighted by Golato's (2005) in-depth analysis of collection methodology. Principally, recordings of naturally occurring talk-in-interaction provide the benefit of repeated and detailed analysis of spoken utterances.

Golato (2005) conducted an in-depth analysis of the advantages and disadvantages of different data collection procedures for the research of compliments and compliment responses. Specifically, she contrasted compliment responses collected through recordings of naturally occurring utterances/communication and elicited data collected via a discourse completion task (DCT). Golato found that recording naturally occurring talk-in-interaction enables the researcher to study how language is organized and realized in natural settings. On the other hand, responses elicited using DCTs indirectly reflect the participant's impression of prior experience with language. In particular, the DCT methodology at times produces data that the participants believe to be natural, or that they think is a proper response, but that in reality does not reflect naturally occurring talk.

Additionally, Golato examined existing research regarding data collection methodology and discussed the advantages and disadvantages of DCTs, questionnaires, recall protocols, role-play, field observation, and recordings of naturally occurring talk-in-interaction. The advantages of DCTs and questionnaires include the ease with which one can control variables and the ability to quickly collect a large amount of data. 
However, the data produced often has a questionable validity when compared to naturally occurring talk because it is not produced as a result of conversational interaction.

Similarly, one advantage of recall protocols is the ability to easily gather a large amounts of data, however, studies have shown that participants are not able to accurately recall syntactic structures.

Role-plays are also relatively easy to administer and, in comparison to recall protocols and DCTs, role-plays produce more natural data. However, the interactions are motivated more by the researcher's pre-determined goals, with participants acting out how they imagine someone in the situation would speak. The subjects may imagine and utilize roles that they have never actually played in real life.

In contrast, field observation has the advantage of the direct study of naturally occurring events while also allowing the researcher to collect a large volume of data. The disadvantages of field observation are that field researchers are essentially unable to control variables and that researchers have to rely on their memory and observational skills. They may thus end up missing important details of the interactions.

Finally, unlike questionnaire data, recordings of naturally occurring talk-in-interaction provide the benefit of repeated and detailed analysis of spoken utterances that occur in a natural, spontaneous context. The disadvantage is that it is difficult to gather a corpus of data large enough for statistical analysis. In addition, the presence of recording equipment is likely to influence the participants. Golato argued, however, that the influence of recording equipment lessened as participants became more accustomed to its presence. 
In sum, Golato concluded that recording naturally occurring conversation was the data collection method best suited for the observation of natural, interactive speech. DCTs and questionnaires were suggested to be best suited for the determination of social and cultural norms. Moreover, field observation — if done carefully and with sensitivity to the interactional contexts - could be useful for the observation of content and basic syntactic and semantic features.

As noted earlier, this study aims to analyze in detail compliment response strategies observed in naturally occurring interaction and to determine if response strategies vary depending on the compliment topic. Consistent with Golato's analysis, recordings of naturally occurring conversation provided the best means of achieving these goals by providing the benefit of repeated and detailed analysis of spoken utterances that occur in a natural, spontaneous context.

However, as also noted by Golato, recordings of naturally occurring conversation provided a considerable disadvantage, in that it is normally difficult to gather a corpus of data large enough for statistical analysis. The first pilot study, described in Section 3.2, highlighted that point, as the participants made few compliments. While the recording of naturally occurring interaction ensures reflection of real language use, the challenge remains that a set of target topics may not be covered in every conversation. In order to overcome this challenge, it was decided that the conversation leader would issue compliments into the conversation according to a very loose agenda. Specifically, conversation leaders were able to ensure that the corpus would provide sufficient utterances in response to each target compliment topic and that a 
significant amount of compliment responses could be gathered within a reasonable number of observed conversations. Moreover, because the conversation leaders remained consistent within each study group, the design provided consistency in the manner in which the data was gathered.

One drawback of involving a conversation leader in the conversation was that the conversations produced may have been, to some extent, less natural than a conversation between two participants. While the focus of the study was compliment response, the participants were not aware of it since they had been informed that they would be asked to talk about their experiences. The conversation leaders subtly inserted compliments into the free-flowing conversation, and, as a result, the participants did not become conscious of their responses to compliments. Thus, it was concluded that the degree to which the research setting, including recording devices, affected the compliment responses that formed the basis of the study was minimal.

\subsection{Data Collection Procedure}

$\underline{\text { Baba } 1999}$

The data collection procedures used in this study are substantially patterned after the procedures used in Baba's (1999) study. Baba asked sixty “discussion leaders" to bring one friend for a thirty minute conversation at a coffee shop or other casual meeting place. The leaders were not instructed that they were required to give compliments but, prior to the conversation and before the participants arrived, the researcher gave them "hints" that they should freely give compliments where they felt natural. The 
conversation was audio recorded while the researcher secretly watched the conversation from a distance. The audio recordings were then transcribed.

Baba distinguished conversation leaders from interviewers. While an interviewer uses formal language within a formal context, conversation leaders were acquaintances or friends of the subjects. Baba's conversation leaders were entirely free to develop the conversation in any way they liked and to create a casual register throughout the conversations. Their only constraints were to cover the topics that were required for the research and to insert compliments and other positive compliments when they felt such expressions natural and relevant. In this way, conversations were only minimally controlled by the researcher.

Baba noted that one advantage of her data collection techniques was that the subjects were not aware that they were being tested and, as a result, were less self-conscious about their compliment responses. However, she also noted that a disadvantage of her data collection technique was that there was no guarantee that all the necessary types of compliment responses needed for the comparison study would be elicited.

The Present Study

Compliment responses were collected in the present study in casual conversations between a participant and a researcher or research assistant acting as a conversation leader. Compliments were made throughout the conversation based on information gathered in a pre-conversation survey as well as on other information mentioned by the participants during the conversation. Compliments were made on 
several target compliment topics. Target compliment topics were the participant's personal appearance, characteristics, abilities, achievements, and clothing/belongings. Conversations were video recorded. Compliments and compliment responses were then transcribed and coded with semantic formulae.

The researcher - a native Japanese speaker — acted as the conversation leader for the Japanese study group, while the research assistant—a native English speaker - acted as conversation leader for the English study group. The research assistant was informed of the topic and goals of the study and trained on how to conduct the conversation.

The conversation leaders attempted to make at least one compliment for each target compliment topic over the course of the conversation. However, both conversation leaders adhered to a rule that compliments should only be made if, in the conversation leader's judgment, the compliment would be natural in the relevant circumstances. Conversations were conducted as a casual conversation. During all portions of the conversation, the researcher made compliments based on subject matter provided by the participant in the pre-conversation survey or on subject matter conveyed by the participant during the conversation. The participant survey was designed to address subject matter that would facilitate the introduction of the specific compliment topics. Those compliment topics are listed in Table 1. 
Table 1 Compliment topic categories

\begin{tabular}{|l|l|}
\hline Topic & Content of the compliments \\
\hline Appearance & Compliments about the subject's face \\
\hline Characteristic & Compliments about the subject's personal characteristics \\
\hline Ability & Compliments about things the subject can do well \\
\hline Achievements & Compliments about things the subject has achieved \\
\hline Belongings & Compliments about the subject's clothes or belongings \\
\hline
\end{tabular}

Collected data was evaluated by third-party native speakers. These speakers

reviewed a representative example of the research data and if, in this validation process, any issues were noted with the interactions, the data, or the data collection procedures, all related data samples were reviewed and those deemed to be unauthentic were eliminated. Compliments that repeated the content of a preceding compliment were also excluded from the data, in order eliminate inconsistencies between the complimenting styles of the researcher and research assistant.

\section{The Present Study Compared to Baba 1999}

The similarities between the present study and Baba's study are substantial. Most significantly, both involve the recording of naturally occurring compliment responses and the use of conversation leaders to insert compliments into otherwise free-flowing conversations.

There are, however, several differences between this and Baba's study. In Baba's study conversation leaders were friends and acquaintances of the participants, while in this study conversation leaders were the researcher and research assistant, respectively, and conversation leaders and the participants were strangers. Moreover, the 
present study used the pre-conversation survey to guide the conversation and as a source of subject matter for compliments, while Baba's study was based upon photos brought by participants and more generalized conversational topics.

As noted by Baba, the use of friends and acquaintances as conversation leaders had the benefit of promoting informal speech, as a consequence of the close relationship between the participants and because the participants were left alone without the presence of a researcher or research assistant. While set in a different social context, efforts were made in the present study to promote a casual setting by downplaying the conversation leader's role as researcher or research assistant, emphasizing her status as a fellow university student, and by eschewing formal trappings and language common to interviews.

\subsection{Participant Recruitment and Participant Experience}

Posters calling for volunteers to take part in a study on "student narrative" were displayed on the Portland State University campus. Personal communications were also used for recruitment. The materials and communications invited participants to take part in a casual conversation and requested that interested individuals contact the researcher by email.

The researcher then separately contacted the prospective research participants via email and scheduled a date and time for a conversation. Before the conversation, each participant was asked to complete a survey asking about his or her achievements, abilities, and positive and negative traits. The information provided by the participants' responses to the survey served as the topical basis for the observed conversations. 
When the participants arrived to take part in the conversation, they were asked to complete a demographic information questionnaire. Information requested on the questionnaire included gender, length of stay in the United States (for Japanese participants), and language background. Participants were also asked to sign a consent form. A video camera recorded the participants from the time they signed the consent form. The camera was placed in clear view near the table where the conversation occurred.

\subsection{Instruments}

\section{Demographic Information Questionnaire}

The demographic information questionnaire was carried out to learn more about the participants' background information. Both study groups were asked to supply their name, gender, and age; the Japanese participants were also asked about their length of stay in the United States. The participants were asked to complete the questionnaire once they arrived for their conversation. See Appendix 2 for a copy of the demographic information questionnaire.

\section{Pre-Conversation Survey}

The pre-conversation survey was used to provide subject matter to guide the conversation. Participants were emailed the survey and asked to return it to the researcher at least a day before the scheduled day for their conversation. The participant survey was designed to address subject matter that would facilitate the introduction of the target compliment topics and also serve as the topical basis for the observed conversations. Specifically, the pre-conversation survey asked each participant about his or her 
achievements, abilities, and positive and negative traits. See Appendix 3 for a copy of the pre-conversation survey.

\subsection{Data Analysis Procedure}

Compliment responses gathered from the conversation recordings were first transcribed and then classified according to the following categories: Acceptance, Rejection, or Avoidance. Frequencies of the three response categories were compared between the two language groups and among topics. Furthermore, the response data were analyzed in terms of semantic formula. A semantic formula is a component of a speech act that represents the means by which a particular speech act is accomplished in terms of the primary content of an utterance (Bardovi-Harlig, 2006). A set of semantic formulas relevant to compliment response was established based on the previous studies as well as the data obtained in this study. The semantic formulas were coded and their frequencies were counted to find any tendencies in the use of semantic formulas and establish their relationship with compliment topics. In the following sections, a short discussion on the response classification will be presented, and the semantic formula analysis will be explained.

\section{Response Segment Coding: Acceptance / Rejection / Avoidance categorization}

The response categories are based on the taxonomy originally proposed by Holmes (1988) (Holmes used the terms Deflect / Evade rather than Avoidance). As noted in Chen (2010), Holmes's taxonomy reflects the insights of Pomerantz's (1978) constraints: the need to agree with the complimenter motivates the acceptance of a compliment, the need to avoid self-praise motivates the rejection of a compliment, and 
the need to strike a balance between the two constraints leads to utterances that mitigate the compliment by avoiding it. Chen notes that Holmes's taxonomy views the three response categories as three regions of an Accepting-to-Rejecting continuum, across which researchers can create subtypes tailored for their own corpus.

According to Holmes's taxonomy, responses are categorized based on how the credit attributed by a compliment is dealt with. Responses that explicitly or implicitly accept the credit attributed by a compliment are deemed to be Accepted. Responses that indicate that the addressee does not agree with the complimenter function as rejections of the credit attributed and are deemed to be Rejected. The Avoidance category is a response that deflects or shifts the credit elsewhere, or evades acknowledgement of the positive effect expressed by the complimenter. Such evasion can also be achieved, Holmes states, by providing a semantically relevant informative response which simply ignores the positive affect expressed by the compliment, or it is sometimes achieved by a response that simply ignores the compliment and changes the topic.

Table 2 Holmes' compliment response categorization

\begin{tabular}{|l|l|}
\hline Accept & $\begin{array}{l}\text { Appreciation or agreement token: e.g., thanks, yes, or smile. } \\
\text { Agreeing utterance: e.g., I think it's lovely too. } \\
\text { Downgrading or qualifying utterance: e.g., it's not too bad is it. } \\
\text { Return compliment: e.g., you are looking good too. }\end{array}$ \\
\hline Reject & $\begin{array}{l}\text { Disagreeing utterance: e.g., I'm afraid I don't like it much. } \\
\text { Question accuracy: e.g., is the beautiful the right word? } \\
\text { Challenge complimenter's sincerity: e.g., you don't really mean that. }\end{array}$ \\
\hline $\begin{array}{l}\text { Deflect/Evade } \\
\text { (Avoidance) }\end{array}$ & $\begin{array}{l}\text { Shift credit: e.g., my mother knitted it. } \\
\text { Ignore: e.g., it's time we were leaving isn't it? } \\
\text { Informative comment: e.g., I bought it at the Vibrant Knits place. } \\
\text { Legitimate evasion: e.g., C. Hey they're nice. Where'd you get them } \\
\text { from? } \\
\text { R. You know, that shop in Cubacade. }\end{array}$ \\
\hline
\end{tabular}


Holmes also stresses the importance of discourse context in classifying compliment response utterances. Identical forms, she states, can have very different implications in different contexts. For example, Holmes provides the following exchange:

C. I love your coat. It looks cozy and warm.

R. It was my mother's. I don't usually like old things but I do like this. $\mathrm{C}=$ Compliment; $\mathrm{R}=$ Response

The response contains an informative comment, "It was my mother's," which, in isolation, could function as an evasion. However, in the end, the responder explicitly accepts the credit by saying, "I do like this." So within the context of the complete compliment response, the informative "It was my mother's" comment acted more to reduce the amount of credit accepted or to act as a contribution to the conversation, rather than as a means of evading the compliment. Thus, an utterance belonging to a sub-category of one classification may operate within its particular context to produce an overall meaning better coded under a different classification.

Due to the impact of context, Holmes coded the response once, on the basis of the overall meaning or function of the response, rather than on the basis of the form of the utterance or utterances making up the response. The present study followed Holmes's approach. Each response was classified into one of the three classifications of Accept, Reject, or Avoidance based on the overall meaning or function of the response, rather than on the basis of the form of the utterance or utterances making up the response.

After categorizing the compliment responses into three categories, the frequencies of each response type were compared (1) between the language groups, (2) 
across the topics in each language group, and (3) between the language groups in terms of the topics. The 'frequency of appearance' calculation represents how often (expressed as a percent) the response category was used in observed compliment responses. frequency of appearance $=$ number of occurrences of the response type $\mathrm{X} 100$ Total number of responses

The findings illustrate the general response strategies utilized in the target data. $\underline{\text { Semantic Formula Coding and Analysis }}$

Next, the data was examined through a semantic formula analysis in order to provide a more nuanced analysis of the response strategies utilized. Bardovi-Harlig (2006) defines semantic formulas as a representation of the means by which a particular speech act is accomplished in terms of the primary content of an utterance.

In this study, the semantic formulas provided in the Coding Chart below were identified and counted. The semantic formulas and examples are adapted from those utilized by Baba (1999) and Shimizu (2009). The "I hope so" and "acknowledgement" formulas were added in order to reflect the present study's corpus. Those formulas that were used by Baba or Shimizu but not observed in the data (such as "expressing regret" and "offer") were eliminated. The semantic formulas in the Coding Chart represent the majority of the verbal and non-verbal means that were used to achieve the acceptance, rejection, and avoidance responses observed in the data. 


\section{Table 3 Coding Chart}

\section{ACCEPTANCE TOKenS}

$\mathrm{C}=$ Compliment; $\mathrm{R}=$ Response

\begin{tabular}{|c|c|}
\hline $\begin{array}{l}\text { Agreement (Seek } \\
\text { Agreement) }\end{array}$ & $\begin{array}{l}\text { "Yeah", "yes", repeating a part of what the preceding speaker has said, } \\
\text { and so on. Claims common ground with the complimenter and } \\
\text { suggests a closeness between the two interactants. } \\
\text { Ex) C: It's good that you don't panic too much. } \\
\text { CR: right, yeah }\end{array}$ \\
\hline Gratitude & $\begin{array}{l}\text { Being thankful or showing appreciation for the compliment. } \\
\text { Ex) C: I like your jacket. } \\
\text { CR: Thank you so much. }\end{array}$ \\
\hline Expressing gladness & $\begin{array}{l}\text { Expressing happiness or pleasure for receipt of the compliment. } \\
\text { C: Waruguti toka iwanaisi, itumo mawari ni ki o tukatteiru hito desu } \\
\text { to. } \\
\text { CR: Uresii desu. }\end{array}$ \\
\hline $\begin{array}{l}\text { Upgrade } \\
\text { (Exaggerate) }\end{array}$ & $\begin{array}{l}\text { Exaggerates the compliment and usually adds details and stories about } \\
\text { the topic. Expresses appreciation for the compliment and intensifies } \\
\text { the interest to hearer by developing the topic of the compliment into an } \\
\text { interesting explanation. } \\
\text { Ex) C: well, that sounds like a great experience. } \\
\text { CR: (smile) yeah, it was perfect. }\end{array}$ \\
\hline $\begin{array}{l}\text { Explanation } \\
\text { (Intensifying Interest } \\
\text { to Hearer) }\end{array}$ & $\begin{array}{l}\text { Explain what is complimented. } \\
\text { Ex) C: Iyaringu kawaii desu ne. } \\
\text { CR: Kotti de kaimasita. }\end{array}$ \\
\hline $\begin{array}{l}\text { Return compliment } \\
\text { (Assume } \\
\text { Reciprocity) }\end{array}$ & $\begin{array}{l}\text { Attempt to return the compliment. } \\
\text { Ex) C: I really like your scarf. } \\
\text { CR: oh I was just thinking about how much I like your scarf and I } \\
\text { was just thinking she's got a great outfit }\end{array}$ \\
\hline
\end{tabular}




\begin{tabular}{|l|l|}
\hline Joke & $\begin{array}{l}\text { Putting the hearer at ease by playfully making light of social } \\
\text { constraints. For example, a complimentee may brag in a joking } \\
\text { manner, thus playfully mocking the social constraint against } \\
\text { self-praise. } \\
\text { Ex) C: sonna ni benkyoo siteta n desuka, sugooi } \\
\text { CR: un, moo sono toki no jibun no tume no aka wo senjite nomitai } \\
\text { gurai na n desu kedo, hontoo ni. hahaha. }\end{array}$ \\
\hline I hope so & $\begin{array}{l}\text { Expressing the desire for the compliment to be true. } \\
\text { Ex) C: (Hanasi o) kite hosii hito ni wa hontoo ni arigatai desu yo ne. } \\
\text { CR: da to ii n desu kedo. haha. }\end{array}$ \\
\hline
\end{tabular}

\section{REJECTION TOKENS}

\begin{tabular}{|l|l|}
\hline Deny & $\begin{array}{l}\text { "Sonnakoto naiyo" and "tondemoarimasen." Rejecting the offer of } \\
\text { praise. } \\
\text { Ex) C: Sikkari sitemasu ne. } \\
\text { CR: Iyaiyaiya, sonna koto nai desu. }\end{array}$ \\
\hline $\begin{array}{l}\text { Questions and } \\
\text { Hedges }\end{array}$ & $\begin{array}{l}\text { Raises a question or shows hesitancy about accepting the compliment } \\
\text { being paid. } \\
\text { Ex1 ) C: I LIKE THAT PICTURE (Baba, 1999) } \\
\text { CR: is that right? (Question) } \\
\text { Ex2) C: sore wa iidesu ne. } \\
\text { CR: u::n doo na n desu kanee. }\end{array}$ \\
\hline $\begin{array}{l}\text { Self-Mockery } \\
\text { Give Deference) }\end{array}$ & $\begin{array}{l}\text { Humbling oneself, usually in a humorous or sarcastic manner displaying } \\
\text { Ex1) C: That takes a lot of guts just going off and doing stuff like that } \\
\text { CR: (nod) well, or bold headedness (laugh) } \\
\text { Ex2) C: sugoi, sonna ni (yakyuu)sitteru n desuka. } \\
\text { CR: iya, tada no yakyuu baka na n de. }\end{array}$ \\
\hline
\end{tabular}




\section{Avoidance Tokens}

\begin{tabular}{|c|c|}
\hline $\begin{array}{l}\text { Credit Shift } \\
\text { (Displace H) }\end{array}$ & $\begin{array}{l}\text { The speaker shifts the credit of a compliment to someone else in order to } \\
\text { avoid the speech act of compliment response. Pretending that the target } \\
\text { of the compliment is not the complimentee but someone else. } \\
\text { Ex) C: Iti-byoo de kotaerareru yoo ni natta n desu ka? Sugoi desu ne. } \\
\text { CR: Soo, gyaku ni sono sensee no okage de waseda ni haireta } \\
\text { mitaina. }\end{array}$ \\
\hline $\begin{array}{l}\text { Downgrade } \\
\text { (Understate) }\end{array}$ & $\begin{array}{l}\text { Understating by denying the upper extremes of the compliments. It has } \\
\text { the implication of agreement to some extent, but to a lower referent. } \\
\text { Ex) C: Wow, that's impressive. } \\
\text { CR: yeah, I'm not about to go to the Olympics or anything like that, } \\
\text { it's just a good solid time, }\end{array}$ \\
\hline $\begin{array}{l}\text { Hint } \\
\text { (Give Hints) }\end{array}$ & $\begin{array}{l}\text { The speaker gives reasons or motivations instead of responding to the } \\
\text { compliment. (It avoids the act of agreeing with the compliment by } \\
\text { giving a reason by which the compliment may be agreed upon.) } \\
\text { Ex) C: So, you are very flexible with your creativity. } \\
\text { CR: I just like writings }\end{array}$ \\
\hline Change Topic & $\begin{array}{l}\text { An intentional change of topic. } \\
\text { Ex) C: Kawaii iyaringu desu ne. } \\
\text { CR: Kocchi, zenzen iyaringu utte nai desu yone, tomodachi ga } \\
\quad \text { nakusimakutte komatte masita. }\end{array}$ \\
\hline Silence & $\begin{array}{l}\text { A decision to remain silent. A gap longer than } 0.8 \text { seconds is considered } \\
\text { significant in Conversation Analysis. } \\
\text { Ex) C: yoku ganbatta n desu ne. } \\
\text { CR: gap (1.0) haa }\end{array}$ \\
\hline Acknowledgement & $\begin{array}{l}\text { An expression or gesture showing that the compliment has been } \\
\text { recognized or noticed. } \\
\text { Ex) C: hantai ni iu to, sore wa ii tokoro desu yo ne. } \\
\text { CR: aa, naro hodo. }\end{array}$ \\
\hline Non-response & Providing no verbal or non-verbal reaction to the compliment. \\
\hline
\end{tabular}




\begin{tabular}{|l|l|}
\hline Sociable Laughter & $\begin{array}{l}\text { A response of Aisowarai or nervous laughter. Aisowarai functions as an } \\
\text { indispensable lubricant for smooth conversational interaction. "Nervous } \\
\text { laughter", arises when the speaker finds the compliment embarrassing or } \\
\text { funny. } \\
\text { Ex1) C: haa sugooi kurieitibuna kanji } \\
\text { CR: gh hhh hhh (Aisowarai) } \\
\text { Ex2) C: KAKKOII NAA } \\
\text { CR: AGH Huh huh }\end{array}$ \\
\hline
\end{tabular}

After categorizing the compliment response, the frequency of appearance and usage ratio of each semantic formula was calculated for each language group and for each topic within each language group. The frequency of appearance calculation represents how often each semantic formula was used in observed compliment responses while the usage ratio represents how much each semantic formula was used in relation to the total volume of observed semantic formulas.

frequency of appearance $=\frac{\text { number of Semantic Formula occurrences }}{\text { Total number of responses }}$

$\underline{\text { usage ratio }}=\frac{\text { number of Semantic Formula occurrences }}{\text { Total number of observed Semantic formula (within a topic category) }}$

The results for each semantic formula were compared (1) between the language groups, (2) across the topics in each language group, and (3) between the language groups in terms of the topics.

The overall Japanese results were compared to the overall American results, the results for each topic were compared to the results for each of the other topics within the same language group, and the Japanese results for each topic were compared to American 
responses to the same topic. This analysis illustrates the frequency and ratio of semantic formulas utilized in the target data.

Discourse markers, defined as sequentially dependent elements which bracket units of talk (Schiffrin, 1987), were coded but differentiated from the Accept, Reject, and Avoidance formula regions. A discourse marker either has no meaning, a vague meaning, or a reflexive meaning, and thus cannot be accurately characterized as accepting, rejecting, or avoiding the credit attributed by a compliment. However, such markers occurred commonly in the data, and often in repeated structural patterns. As a result, discourse markers were coded in order to examine structural features and also to contribute to the qualitative analysis to follow in the discussion section.

Finally, the semantic formulas were analyzed in terms of sequential and non-sequential co-occurrence of two or more semantic formulas according to the language group and the compliment topic within each language group. It is hoped that this semantic formula analysis provides some insight into the ways in which American and Japanese speakers reconcile the competing needs inherent in the speech act of compliment response. 


\section{CHAPTER 4: \\ RESULTS}

This Chapter presents the quantitative results of the study. Section 4.1 presents the overall rate at which each response type was used by the language groups. Section 4.2 will explore whether compliment topic is related to variations in compliment response by comparing the frequency at which each response type was used across the topic categories. In Section 4.3, the analysis will shift to the ways in which compliment responses were formed and highlight several response patterns used by the subjects. Chapter 5 will then seek to explain the variations in responses across language groups, response types, and compliment topic.

\subsection{Response type classification overall findings}

Table 4 contains the proportions of the three response types in the two language groups. And Figures 1, 2, and 3 are visual representations of the percentages of the Japanese and the English responses respectively.

Table 4 Japanese and English overall results

\begin{tabular}{|c||c|c|}
\hline \multirow{2}{*}{} & \multicolumn{2}{|c|}{ Overall } \\
\hline & JPN (186) & ENG (108) \\
\hline Accept & $30.6 \%(57)$ & $69.4 \%(75)$ \\
\hline Avoidance & $46.2 \%(86)$ & $29.6 \%(32)$ \\
\hline Reject & $23.1 \%(43)$ & $0.9 \%(1)$ \\
\hline
\end{tabular}


Figure 1 Japanese overall results

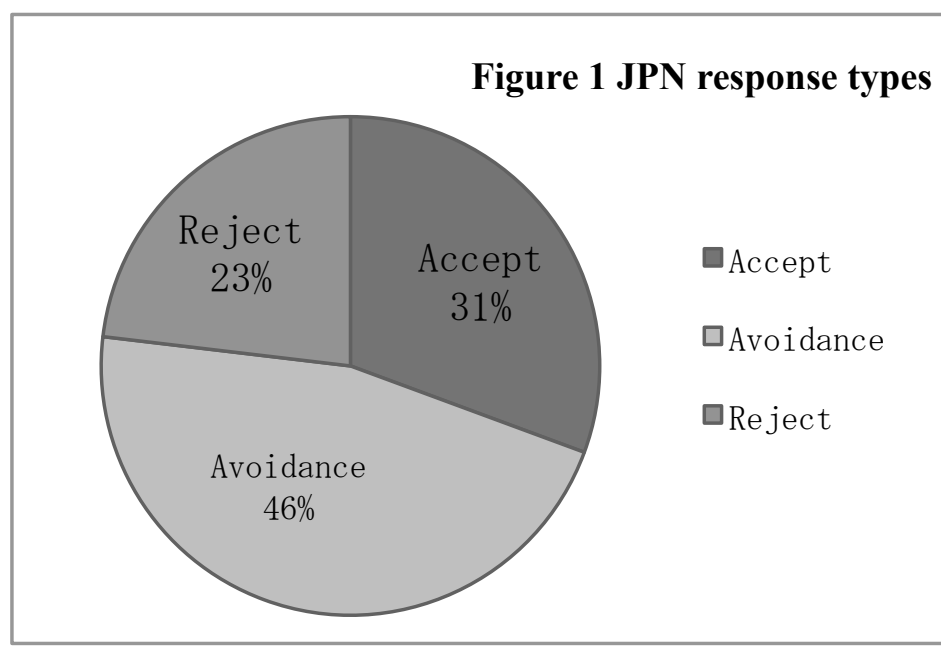

\begin{tabular}{|c||c|}
\hline & JPN (186) \\
\hline Accept & $30.6 \%(57)$ \\
\hline Avoidance & $46.2 \%(86)$ \\
\hline Reject & $23.1 \%(43)$ \\
\hline
\end{tabular}

Contrary to commonly held belief, the Japanese speakers did not overwhelmingly reject compliments, but instead used all three response types with a substantial frequency. The relative usage of the three response types are within a relatively similar range, with the highest percentage at $46.2 \%$ for Avoidance, followed by $30.6 \%$ for Accept and $23.1 \%$ for Reject. Differences in these response rates are not inconsequential, but the substantial incidence of each response type shows that there was no clearly preferred or dispreferred response type within the Japanese group.

This suggests that Japanese speakers may have a wide range of appropriate compliment responses available to them. Alternatively, these results allow for the inference that various factors may play a role when Japanese people choose a response strategy when reacting to a compliment. As this study hypothesizes, one factor related to the preferability of response types may be compliment topic. Section 4.2 will explore these questions in greater detail by examining the relationship between the usage of compliment response types and variations in compliment topic. 
Figure 2 English overall results

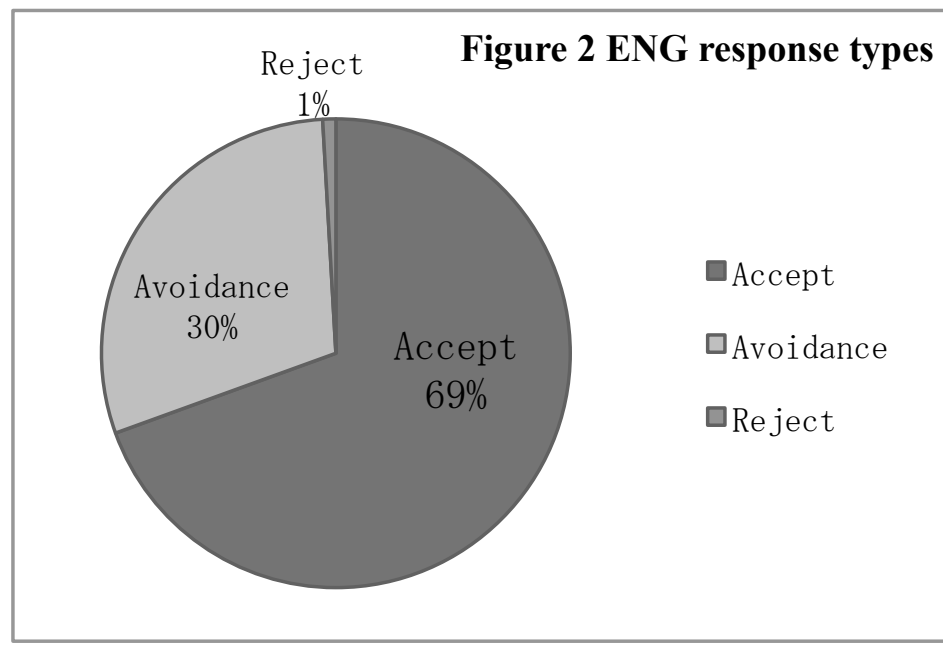

\begin{tabular}{|c||c|}
\hline & ENG(108) \\
\hline Accept & $69.4 \%(75)$ \\
\hline Avoidance & $29.6 \%(32)$ \\
\hline Reject & $0.9 \%(1)$ \\
\hline
\end{tabular}

The American participants overwhelmingly accepted compliments and almost never rejected compliments. Compliments were accepted in $69.4 \%$ of compliment responses but Reject responses were nearly nonexistent, comprising only $0.9 \%$ of response types. Avoidance strategies were also commonly observed, occurring in $29.6 \%$ of responses, and should not be overlooked in the discussion of American English compliment response patterns.

The results demonstrate that rejection was a dispreferred response amongst the English group while acceptance and avoidance response types essentially comprised the entire spectrum of favorable compliment response strategies. For the American subjects, acceptance was clearly an appropriate response under a wide range of circumstances. 


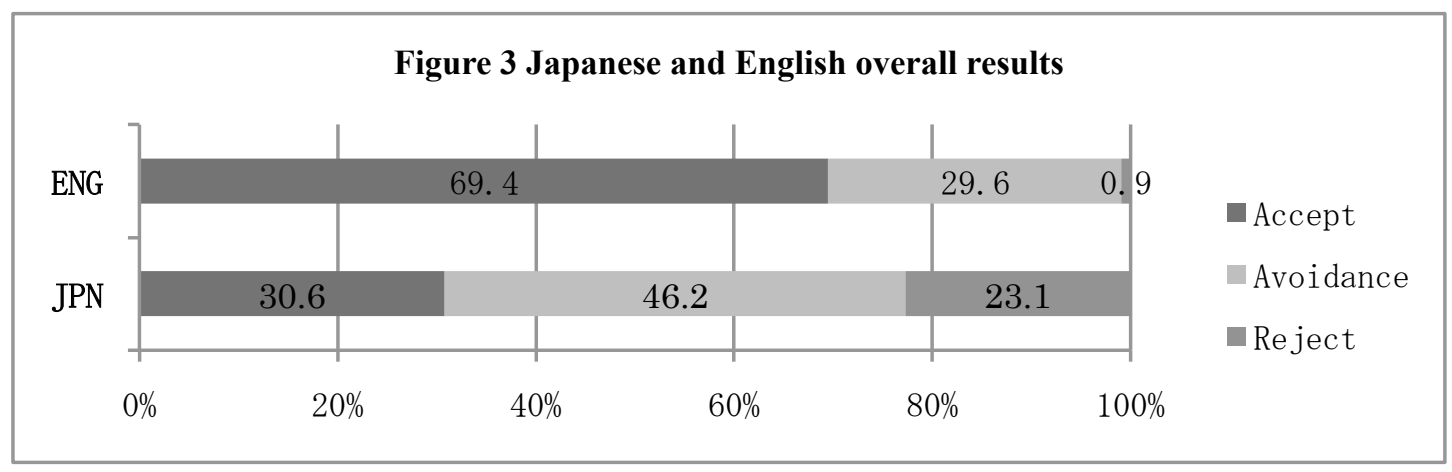

Figure 3 presents the distributions of the three response types in each language group. It reveals that the Japanese subjects were more likely to reject or avoid compliments while the English-speaking subjects were more likely to accept compliments. Less than $1 \%(0.9 \%)$ of the English group's responses were rejection, while $23.1 \%$ of the Japanese responses were rejection. Conversely, the proportion of acceptance by the English group was twice as much as that of the Japanese group. English participants accepted more than two-thirds (69.4\%) of compliments compared to less than one-third acceptance (30.6\%) in the Japanese group. The Avoidance response type presented another substantial contrast, with the Japanese group avoiding $46.2 \%$ of the time and the English group avoiding $29.6 \%$ of the time.

The differences in response types between the two language groups were thus quite remarkable, strongly suggesting that American participants accepted compliments the majority of the time while their Japanese counterparts avoided compliments more often than explicitly accepting or rejecting them. Moreover, the large discrepancy in the type of rejection indicates that while the Japanese group considered rejection to be at least occasionally favorable, the English group used rejection only in the rarest of 
circumstances. In terms of acceptance, the overall result suggests that it is a myth that Japanese never accept a compliment, but, when compared to the American participants, the Japanese participants employed acceptance under a much narrower range of circumstances.

\subsection{Compliment topic category findings}

This Section expands upon the response type findings presented in Section 4.1 by comparing the usage of each response type across the topic categories. Table 5 and Figures 4 and 5 represent the rates at which compliments in the five compliment topic categories were accepted, avoided, or rejected.

Table 5 Japanese and English compliment topic results

\begin{tabular}{|c|c|c|c|c|c|c|c|c|c|c|c|c|}
\hline & \multicolumn{2}{|c|}{ Overall } & \multicolumn{2}{|c|}{ Appearance } & \multicolumn{2}{|c|}{ Characteristic } & \multicolumn{2}{|c|}{ Ability } & \multicolumn{2}{|c|}{ Achievement } & \multicolumn{2}{|c|}{ Belongings } \\
\hline & $\begin{array}{l}\text { JPN } \\
(186)\end{array}$ & $\begin{array}{l}\text { ENG } \\
(108)\end{array}$ & $\begin{array}{l}\text { JPN } \\
(16)\end{array}$ & $\begin{array}{l}\text { ENG } \\
(13)\end{array}$ & $\begin{array}{l}\text { JPN } \\
(65)\end{array}$ & $\begin{array}{c}\text { ENG } \\
(43)\end{array}$ & $\begin{array}{l}\text { JPN } \\
(40)\end{array}$ & $\begin{array}{c}\text { ENG } \\
(10)\end{array}$ & $\begin{array}{l}\text { JPN } \\
(48)\end{array}$ & $\begin{array}{c}\text { ENG } \\
(31)\end{array}$ & $\begin{array}{l}\text { JPN } \\
\text { (17) }\end{array}$ & $\begin{array}{r}\text { ENG } \\
(11)\end{array}$ \\
\hline Accept & $\begin{array}{c}30.6 \% \\
(57)\end{array}$ & $\begin{array}{l}69.4 \% \\
(75)\end{array}$ & $\begin{array}{c}6.3 \% \\
(1)\end{array}$ & $\begin{array}{c}38.5 \% \\
(5)\end{array}$ & $\begin{array}{c}33.8 \% \\
(22)\end{array}$ & $\begin{array}{r}52.8 \% \\
(27)\end{array}$ & $\begin{array}{c}12.5 \% \\
(5)\end{array}$ & $\begin{array}{c}70.0 \% \\
(7)\end{array}$ & $\begin{array}{c}41.7 \% \\
(20)\end{array}$ & $\begin{array}{l}80.6 \% \\
(25)\end{array}$ & $\begin{array}{c}52.9 \% \\
(9)\end{array}$ & $\begin{array}{r}100 \% \\
(11)\end{array}$ \\
\hline Avoidance & $\begin{array}{c}46.2 \% \\
(86)\end{array}$ & $\begin{array}{l}29.6 \% \\
(32)\end{array}$ & $\begin{array}{c}62.5 \% \\
(10)\end{array}$ & $\begin{array}{c}61.5 \% \\
(8)\end{array}$ & $\begin{array}{c}40.0 \% \\
(26)\end{array}$ & $\begin{array}{l}4.9 \% \\
(15)\end{array}$ & $\begin{array}{r}47.5 \% \\
(19)\end{array}$ & $\begin{array}{c}30.0 \% \\
\text { (3) }\end{array}$ & $\begin{array}{r}50.0 \% \\
(24)\end{array}$ & $\begin{array}{c}19.4 \% \\
(6)\end{array}$ & $\begin{array}{r}41.2 \% \\
(7)\end{array}$ & $0 \%$ \\
\hline Reject & $\begin{array}{c}23.1 \% \\
(43)\end{array}$ & $\begin{array}{c}0.9 \% \\
\text { (1) }\end{array}$ & $\begin{array}{c}31.2 \% \\
(5)\end{array}$ & $0 \%$ & $\begin{array}{c}26.2 \% \\
(17)\end{array}$ & $\begin{array}{l}2.3 \% \\
(1)\end{array}$ & $\begin{array}{r}40.0 \% \\
(16)\end{array}$ & $0 \%$ & $\begin{array}{c}8.3 \% \\
(4)\end{array}$ & $0 \%$ & $\begin{array}{c}5.9 \% \\
(1)\end{array}$ & $0 \%$ \\
\hline
\end{tabular}



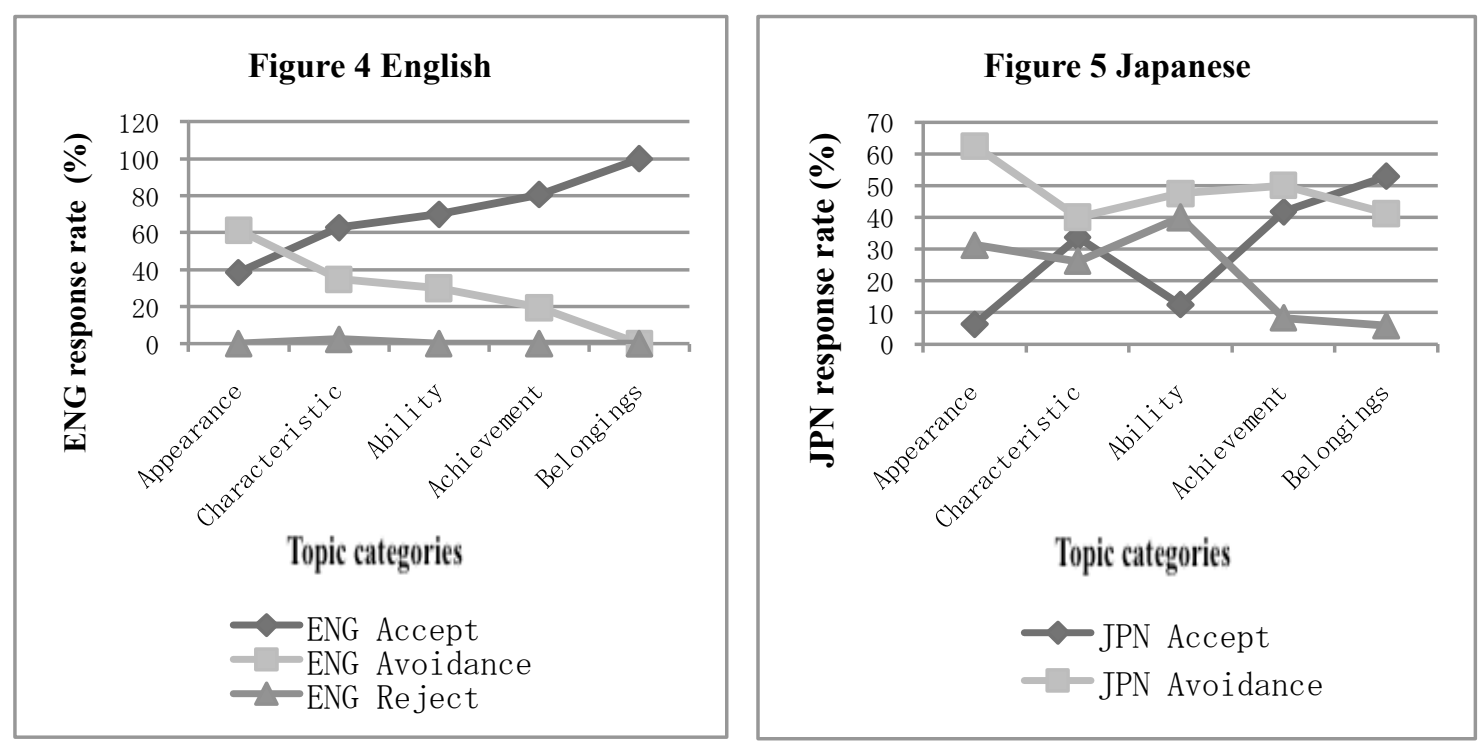

Figures 4 and 5 demonstrate that the American group's responses clearly favor acceptance across almost all the topic categories, while the Japanese group's response distributions vary depending on the topic. Acceptance was the most common response type for the English group in every topic category (characteristics, ability, achievement, and belonging) except for appearance. For the Japanese group, avoidance was the most common response type in every topic category (appearance, characteristics, ability, and achievement) except for belongings. In sum, the Japanese group tended to reject and avoid compliments more than the English group, and English group tended to accept more than the Japanese group, across the five compliment topic categories.

Figures 4 and 5 also demonstrate that response strategies varied relative to compliment topic. As compared to the overall response percentages utilized by each language group, compliments in the appearance topic category were less likely to be accepted and more likely to be avoided in both groups, and more likely to be rejected in 
the Japanese group. Similarly, compliments in the achievement topic category were relatively more likely to be accepted in both language groups. Compliments in the belongings topic category, by contrast, were more likely to be accepted by both language groups, less likely to be avoided in the English group, and less likely to be rejected in the Japanese group. Lastly, responses to compliments in the characteristic and ability categories generally fell between the outer extremes of acceptance and rejection ratios in both groups.

Table 6 English and Japanese acceptance responses

\begin{tabular}{|c|c|c|c|c|c|c|c|c|c|c|c|c|}
\hline & \multicolumn{2}{|c|}{ Overall } & \multicolumn{2}{|c|}{ Appearance } & \multicolumn{2}{|c|}{ Characteristic } & \multicolumn{2}{|c|}{ Ability } & \multicolumn{2}{|c|}{ Achievement } & \multicolumn{2}{|c|}{ Belongings } \\
\hline & JPN & ENG & JPN & ENG & JPN & ENG & JPN & ENG & JPN & ENG & JPN & ENG \\
\hline \multirow{2}{*}{ Accept } & \multicolumn{2}{|c|}{$30.6 \% 69.4 \%$} & $6.3 \%$ & $38.5 \%$ & $33.8 \%$ & $62.8 \%$ & $12.5 \%$ & $70.0 \%$ & $41.7 \%$ & $80.6 \%$ & $52.9 \%$ & $100 \%$ \\
\hline & (57) & (75) & (1) & (5) & (22) & $(27)$ & (5) & (7) & (20) & $(25)$ & (9) & (11) \\
\hline
\end{tabular}

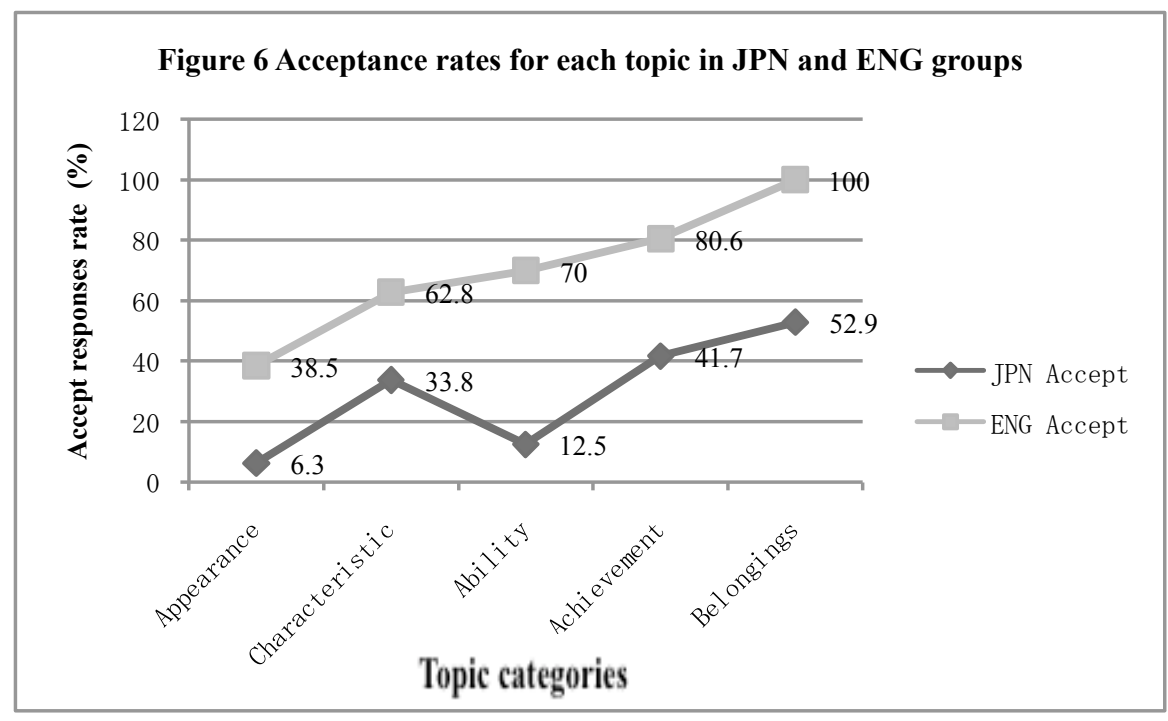

Figure 6 presents the acceptance rates for each compliment topic. It shows a similar pattern of variation in both language groups. Most strikingly, compliments about appearance were accepted at very low percentages (38.5\% for the English group, $6.3 \%$ 
for the Japanese group), while compliments about belongings were accepted at very high percentages (100\% for the English group, $52.9 \%$ for the Japanese group). This result is striking because it presents such a distinct contrast in response strategies, but also because it illustrates the broad range of acceptance rates observed across the compliment topics. Compliments in the achievement topic category were also relatively more likely to be accepted in both language groups ( $41.7 \%$ for the Japanese group and $80.6 \%$ for the English group, which compares to overall acceptance percentages of $30.6 \%$ for the Japanese group and $69.4 \%$ for the English group). The characteristics and abilities topic categories, by contrast, varied very little from the overall acceptance rates of $30.6 \%$ for the Japanese group and $69.4 \%$ for the English group. The one exception was that the percentage of acceptance responses utilized by Japanese subjects was notably low in the ability category.

The overall difference in Acceptance percentages between the language groups was $38.8 \%$. The smallest difference between the Japanese and English groups was $29.0 \%$ in the characteristics topic category and the largest difference was $57.5 \%$ in responses to the ability topic category.

Table 7 Japanese and English rejection responses

\begin{tabular}{|c|c|c|c|c|c|c|c|c|c|c|c|c|}
\hline & Overall & Appearance & Characteristic & Ability & Achievement & Belongings \\
\hline & JPN & ENG & JPN & ENG & JPN & ENG & JPN & ENG & JPN & ENG & JPN & ENG \\
\hline \multirow{2}{*}{ Reject } & $\begin{array}{c}23.1 \% \\
(43)\end{array}$ & $\begin{array}{c}0.9 \% \\
(1)\end{array}$ & $\begin{array}{c}31.2 \% \\
(5)\end{array}$ & $0 \%$ & $\begin{array}{c}26.2 \% \\
(17)\end{array}$ & $\begin{array}{c}(1) \\
(1)\end{array}$ & $\begin{array}{c}40.0 \% \\
(16)\end{array}$ & $0 \%$ & $\begin{array}{c}8.3 \% \\
(4)\end{array}$ & $0 \%$ & $\begin{array}{c}5.9 \% \\
(1)\end{array}$ & $0 \%$ \\
\hline
\end{tabular}




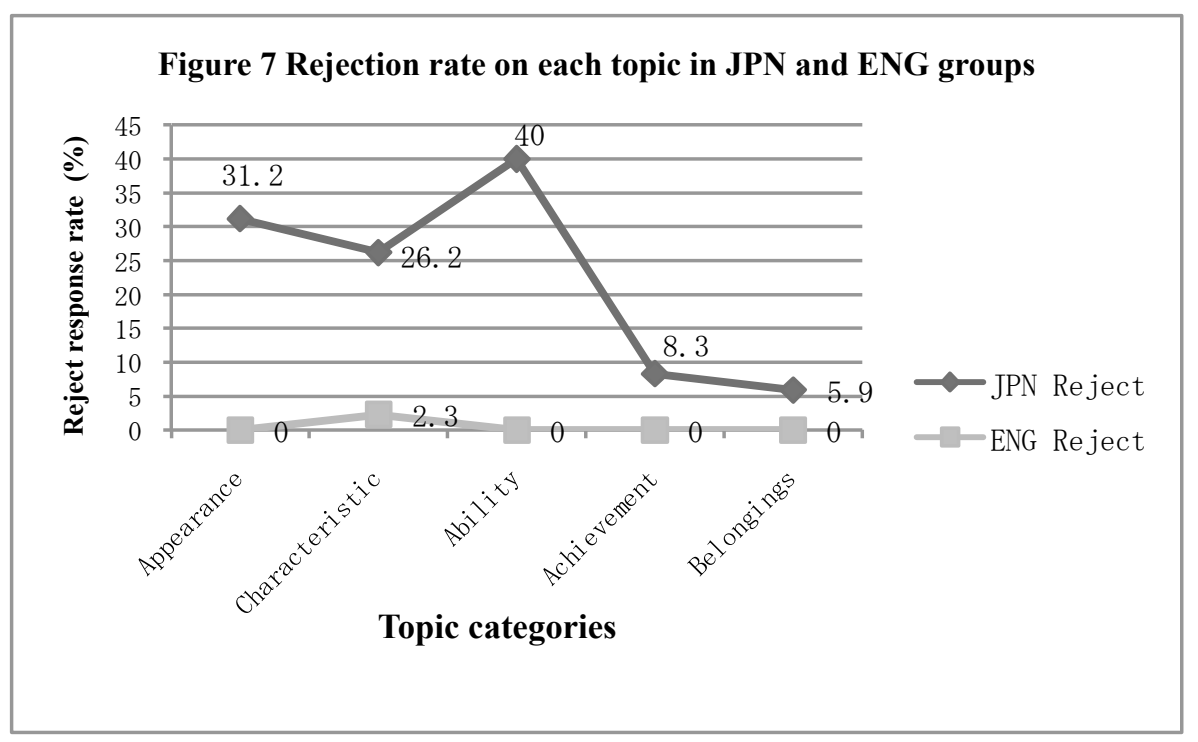

Figure 7 shows the rejection rates to the five compliment topics in the two language groups. The English group did not use rejection in response to any of the topics except for one response in the characteristics category (producing a $2.3 \%$ response rate). As may be expected, the trend in the Japanese rejection rate across the compliment topics was roughly the inverse of the trend observed in the Japanese acceptance rate. The Japanese rejection rate was $31.2 \%$ in the appearance topic category, decreased to $26.2 \%$ in the characteristic category, spiked to $40.0 \%$ in the ability category, and then decreased to low levels of $8.3 \%$ and $5.9 \%$ in the achievement and belongings topic categories.

The overall difference in Reject rates between the language groups was $20.9 \%$. The largest difference was $40.0 \%$ in the ability category and the smallest difference was $5.9 \%$ in the belongings category. 
Table 8 Japanese and English avoidance responses

\begin{tabular}{|c|c|c|c|c|c|c|c|c|c|c|c|c|}
\hline & \multicolumn{2}{|c|}{ Overall } & \multicolumn{2}{|c|}{ Appearance } & \multicolumn{2}{|c|}{ Characteristic } & \multicolumn{2}{|c|}{ Ability } & \multicolumn{2}{|c|}{ Achievement } & \multicolumn{2}{|c|}{ Belongings } \\
\hline & JPN & \begin{tabular}{|l} 
ENG \\
\end{tabular} & JPN & ENG & JPN & ENG & JPN & ENG & JPN & ENG & JPN & ENG \\
\hline Avoidance & $\begin{array}{c}46.2 \% \\
(86)\end{array}$ & $\begin{array}{c}29.6 \% \\
(32)\end{array}$ & $\begin{array}{c}62.5 \% \\
(10)\end{array}$ & $\begin{array}{c}61.5 \% \\
(8)\end{array}$ & $\begin{array}{c}40.0 \% \\
(26)\end{array}$ & $\begin{array}{c}34.9 \% \\
(15)\end{array}$ & $\begin{array}{r}47.5 \% \\
\text { (19) }\end{array}$ & $\begin{array}{c}30.0 \% \\
\text { (3) }\end{array}$ & $\begin{array}{r}50.0 \% \\
(24)\end{array}$ & $\begin{array}{c}19.4 \% \\
(6)\end{array}$ & $\begin{array}{c}41.2 \% \\
(7)\end{array}$ & $0 \%$ \\
\hline
\end{tabular}

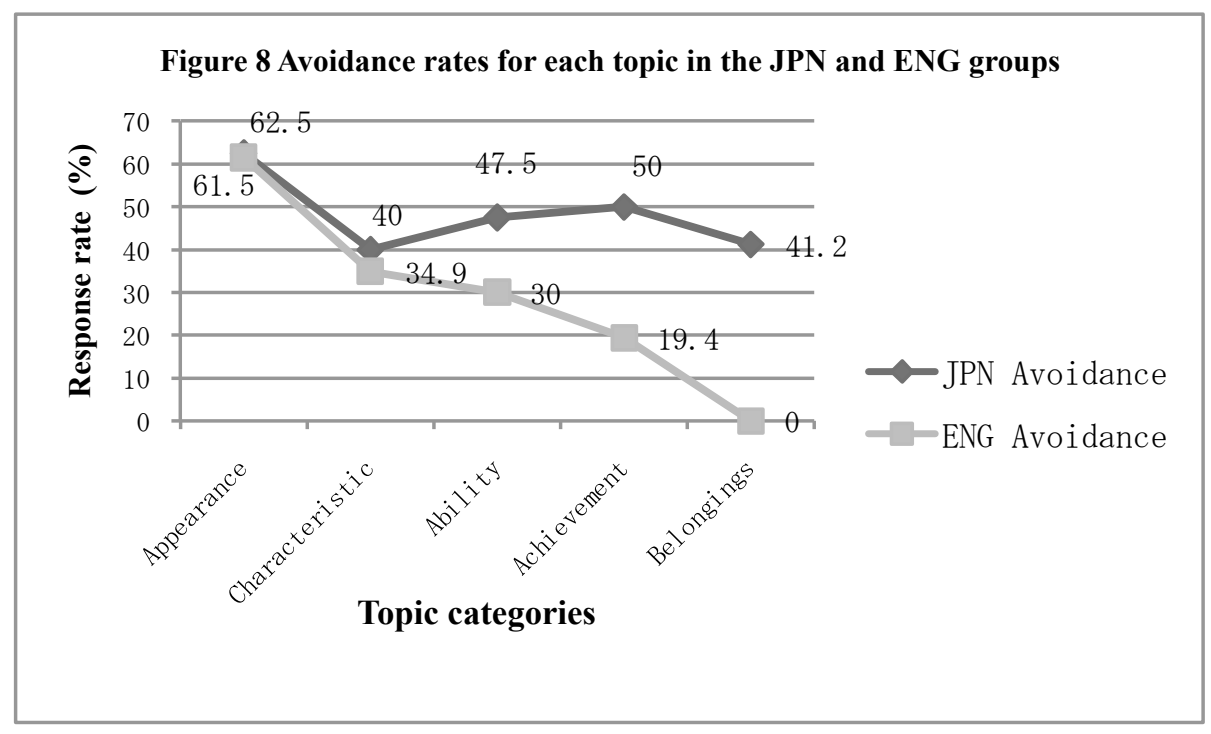

Figure 8 shows the avoidance rate by topic. The English avoidance rate started at a high of $61.5 \%$ in the appearance topic category and decreased steadily to $0 \%$ in the belongings topic category. Meanwhile, the Japanese avoidance rate ranged from $40.0-50.0 \%$ for the characteristic, ability, achievement, and belongings categories but spiked to $62.5 \%$ in the appearance category. Overall, the Japanese group avoided compliments at a $16.6 \%$ higher rate. The largest advantage in Japanese avoidance rate was observed in the belongings topic category (41.2\%), while the smallest advantage was $1.0 \%$ in the appearance topic category. 
The most substantial difference in the response distribution between the English and Japanese groups was observed in the ability topic category. Figure 9 is a bar graph comparing the Japanese and English groups in the ability topic category.

Figure 9 English and Japanese ability topic category results

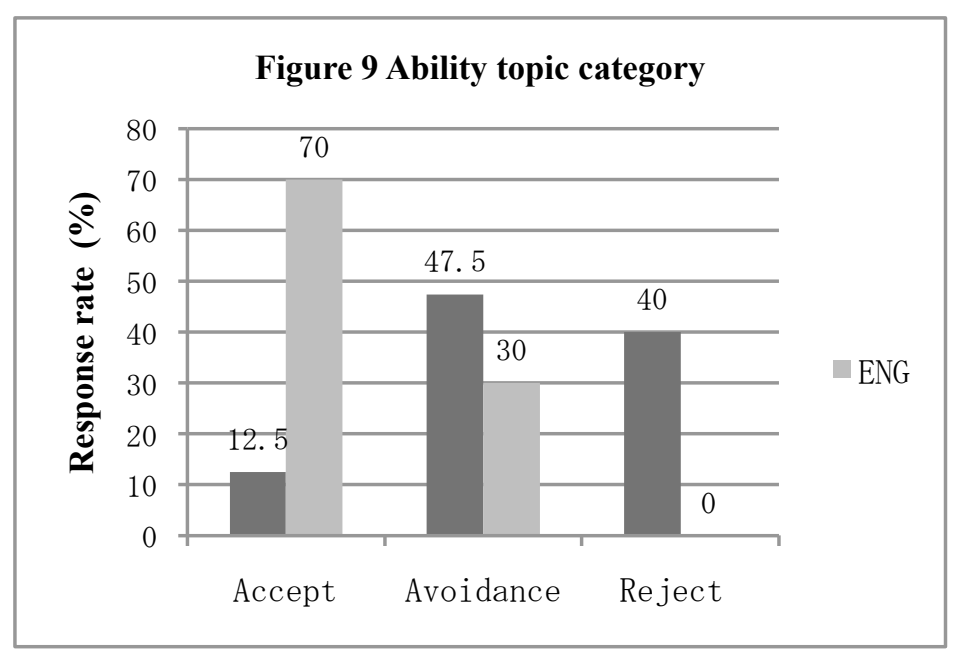

\begin{tabular}{|c||c|c|}
\hline \multicolumn{1}{|c||}{} & \multicolumn{2}{|c|}{ Ability } \\
\hline & JPN & ENG \\
\hline Accept & $12.5 \%$ & $70.0 \%$ \\
\hline Avoidance & $47.5 \%$ & $30.0 \%$ \\
\hline Reject & $40.0 \%$ & $0 \%$ \\
\hline
\end{tabular}

The English group accepted compliments about ability at a $70.0 \%$ rate compared to a $12.5 \%$ rate for the Japanese group. The difference of $57.5 \%$ was the largest gap in Accept rates observed in the language groups. Conversely, the Japanese group rejected compliments about ability at a $40.0 \%$ rate while the English group did not reject any compliments about ability, producing the largest gap in Reject rates observed in the language groups.

\subsection{Semantic Formula Results}

Section 4.1 examined the overall response types used by the language groups. Section 4.2 expanded on those results by demonstrating how response types varied in relation to compliment topic. Now, this Section will further expand upon the findings by 
exploring how the language groups formed their responses. It was hypothesized that Japanese native speakers would tend to mitigate acceptance by adding self-effacing comments while English native speakers would tend to express agreement or gratitude without mitigation. This Section seeks to answer whether the hypothesis was correct. It also seeks to reveal significant patterns of response in relation to category topic and the manner of acceptance, rejection, or avoidance in both language groups.

A semantic formula analysis focuses on the number and type of semantic formulas and semantic formula patterns utilized in the data and compares the frequency with which each formula is used (Saito and Beecken, 1997). This study identified the semantic formulas provided in the Coding Chart (pp. 35-39) within each of the three response types and then counted the number of times each formula occurred. Each semantic formula was organized into Accept, Reject, or Avoidance groupings. A compliment response may consist of more than a single semantic formula, and whether a particular response is categorized into Acceptance, Avoidance, or Rejection, it may contain semantic formulas from various groupings. Examining kinds of semantic formula identified within a response reveals a degree of mitigation. It should be noted that the groupings were made to merely illustrate "regions" on a response continuum, as described by Chen (2010). Many individual semantic formulas would likely fall somewhere in between those regions, if represented on a continuum. Individual semantic formula usage

Figure 10 presents the frequency of appearance of each semantic formula for each language group. The values represent the number of compliment responses in which 
each semantic formula occurred divided by the total number of compliment responses made by the language group. The quotient was then multiplied by 100 to represent the values as percentages. In this way, the values reflect how often the particular semantic formula occurred within the observed compliment responses.

Figure 10 Japanese and English overall semantic formula results

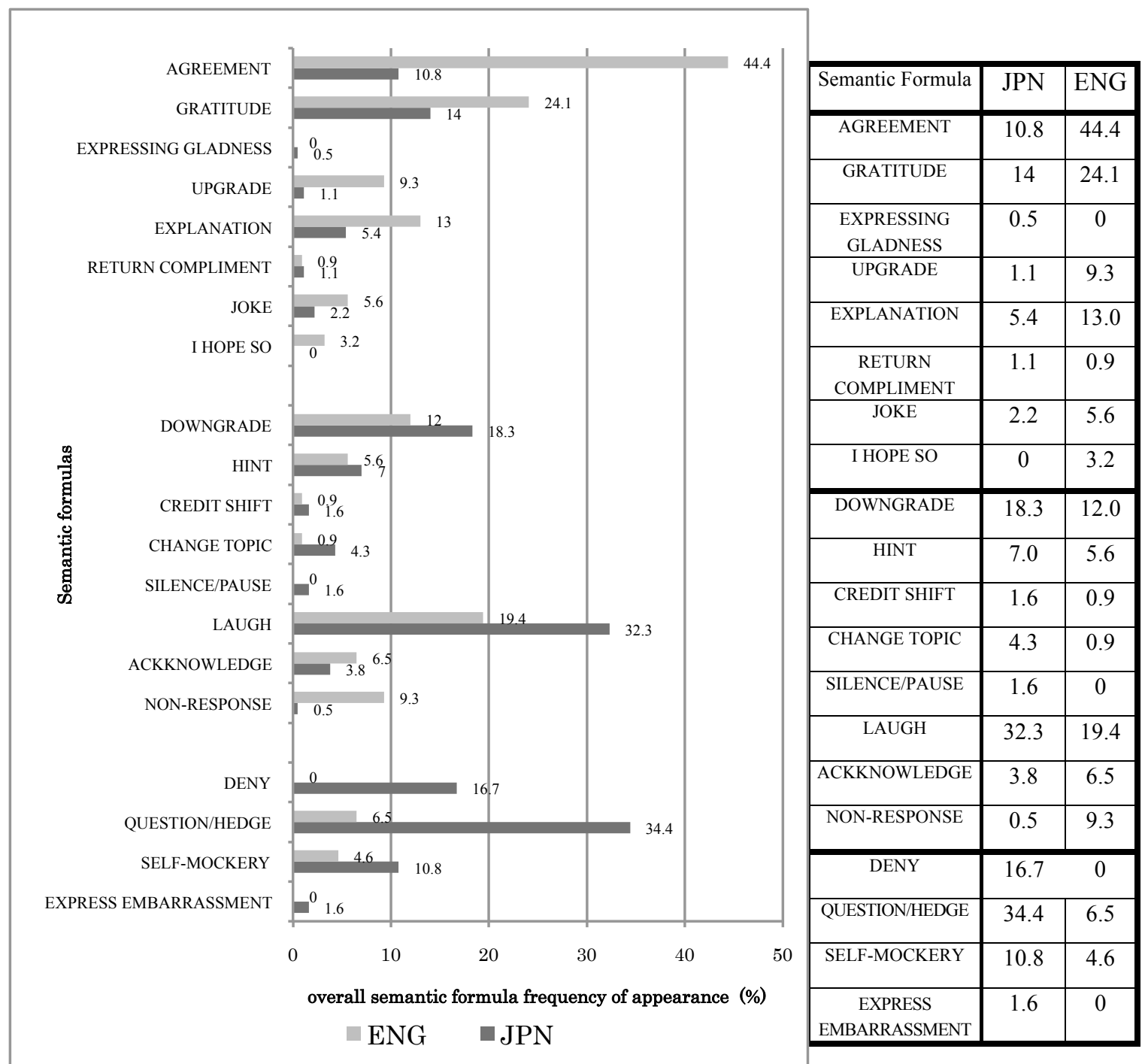

Agreement was the most commonly used formula in the English group, occurring in $44.4 \%$ of the subjects' compliment responses. Gratitude was the second most common at 
$24.1 \%$, followed by laugh (19.4\%), explanation (13.0\%), and downgrade (12.0\%). Question/Hedge was the most commonly used formula in the Japanese group, occurring in $34.4 \%$ of the Japanese compliment responses. Laugh was the second most common semantic formula occurring in $32.3 \%$ of Japanese responses, followed by downgrade (18.3\%), deny (16.7\%), and agreement and self-mockery (10.8\%).

\section{$\underline{\text { Japanese and English Accept responses }}$}

The semantic formulas used by the Japanese and English groups when accepting compliments are presented below.

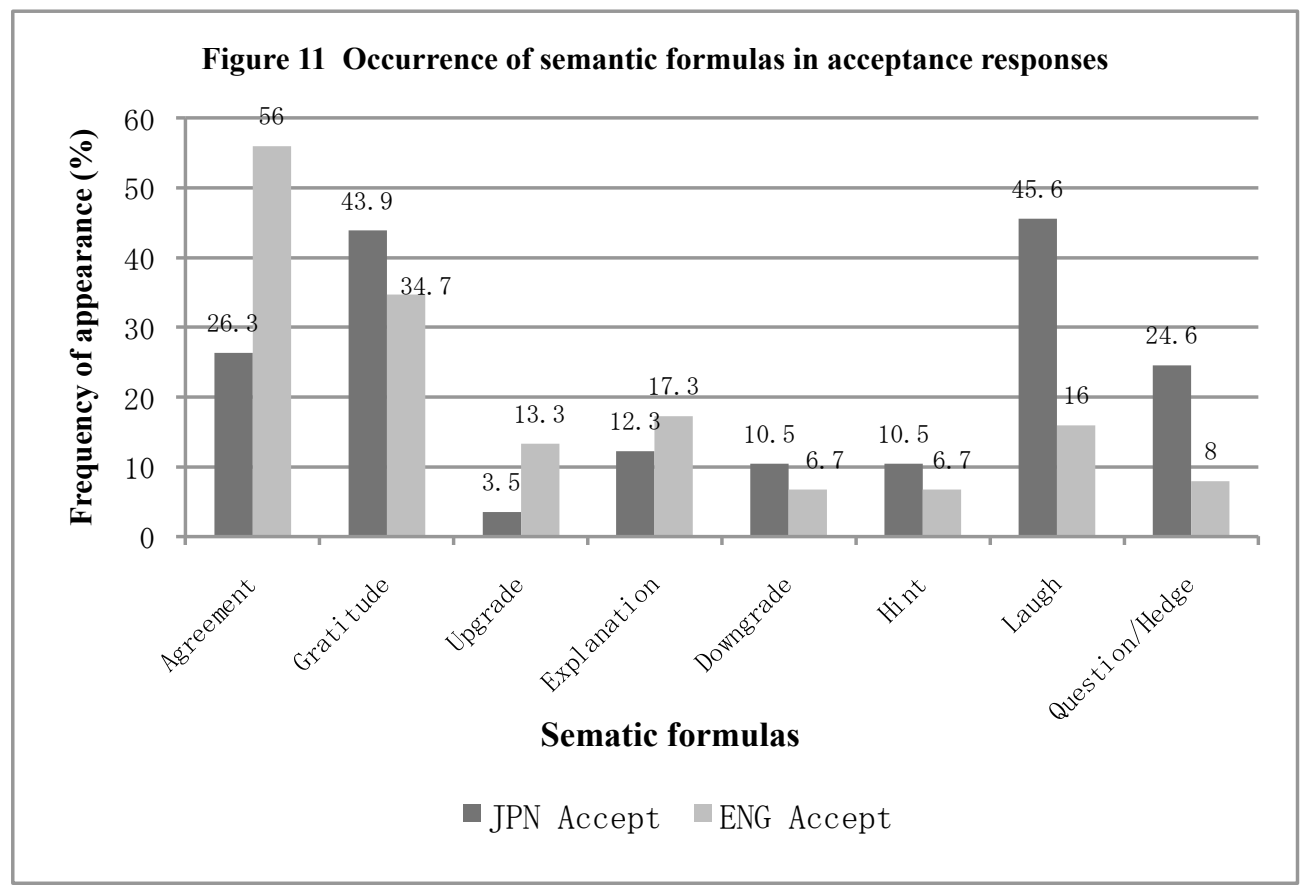

The most common semantic formulas used in the English acceptance responses were agreement (56\%) and gratitude (43.9\%), while explanation (17.3\%), laugh (16\%), and upgrade (13.3\%) were also commonly used. 
As hypothesized, the Japanese native speakers tended to mitigate acceptance while English native speakers tended to express agreement or gratitude without much mitigation. Within the Japanese group's Accept compliment responses, 47.4\% of the semantic formulas utilized were from the Accept formula region, 36.1\% were from the Avoidance formula region, and 15.5\% were from the Reject formula region. By contrast, within the English group's Accept compliment responses, $75.8 \%$ of the semantic formulas used were from the Accept formula region, 18.2\% were from the Avoidance region, and $6.0 \%$ were from the Reject region. These overall findings indicate that the Japanese group used a wider range of semantic formulas in their Accept responses and commonly intermixed semantic components of acceptance with components of avoidance or rejection.

A closer look at the response patterns utilized by the language groups reinforces the finding about the intermixing of semantic formula groupings by the Japanese group. Of the 57 responses in which the Japanese subjects accepted the compliment, only 18 were unmitigated, meaning the response contained no avoidance or rejection semantic formulas. Thus, $31.6 \%$ of the Japanese responses were unmitigated and $68.4 \%$ were mitigated. By contrast, $69.3 \%$ of the English responses (52 out of 75) were unmitigated and only $30.7 \%$ were mitigated. The contrast is fairly striking and illustrates the extent to which the Japanese group sought to minimize and/or qualify the positive remarks attributed to them as compared to the English group.

Of the 18 unmitigated Japanese Accept responses, 9 contained an "“ $A$ ' + gratitude" sequence. The discourse marker "A" occurred in 17 of the 25 responses in 
which gratitude occurred overall and, as will be discussed in Chapter 5, may have communicated a sense of surprise or unexpectedness at receiving the compliment. As a result, even among the Japanese responses that were classified here as unmitigated acceptance, half of them arguably contained a message of implied reluctance or unworthiness.

The English group, by comparison, commonly paired agreement or gratitude and upgrade or explanation semantic formulas. Agreement semantic formulas were paired with upgrade semantic formulas 8 out of 42 times $(19.0 \%)$ and explanations that expanded on the complimented subject matter 7 out of the 42 times $(16.7 \%)$. Gratitude semantic formulas were paired with an upgrading statement only once, but were paired with explanation semantic formulas in 5 out of the $26(19.2 \%)$ responses in which the gratitude formula occurred.

Thus, the English group not only accepted a greater percentage of compliments, as described in Sections 4.1 and 4.2, but there was also a difference between the two groups in the manner in which compliments were accepted. The Japanese subjects tended to mitigate and qualify acceptance, while unmitigated compliment responses were most common in the English group.

\section{Topic specific response patterns}

The usage of agreement corresponded with similar variations in the two language groups for the appearance and achievement topic categories. 
Table 9 Agreement semantic formula usage rate

\begin{tabular}{|c||c||c|c|c|c|c|}
\hline & Overall & Appearance & Characteristic & Ability & Achievement & Belongings \\
\hline Agreement (ENG) & 44.4 & $\mathbf{0}$ & 51.2 & 50.0 & $\mathbf{6 1 . 3}$ & 27.3 \\
\hline Agreement (JPN) & 10.8 & $\mathbf{0}$ & 7.7 & 5.0 & $\mathbf{2 6 . 0}$ & 0 \\
\hline
\end{tabular}

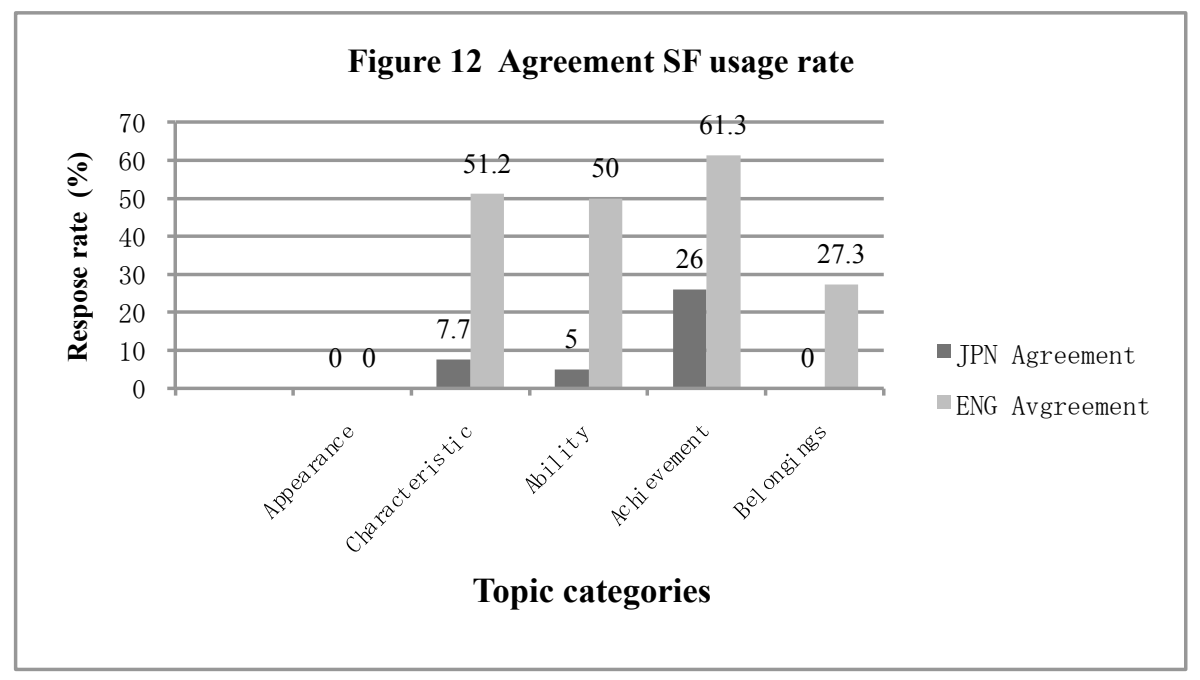

Neither group used agreement in responses in the appearance topic category while the highest usage of agreement in both groups occurred in the achievement topic category (61.3\% for the English group and $26.0 \%$ for the Japanese group). The lack of agreement formulas in the English appearance responses was a marked departure from the high rate of usage found in the other topic categories. Conversely, the high rate of agreement formulas in the Japanese achievement responses differed from the infrequent use of agreement by the Japanese group in the other topic categories.

The semantic formulas usage ratios for the belongings topic category also exhibited a very distinctive response pattern. 
Table 10: Gratitude and $\mathrm{Oh} / A \mathrm{SF}$ usage rate in response to compliments about belongings

\section{English}

\begin{tabular}{|c|c|}
\hline Semantic Formulatypes & Belongings (11) \\
\hline Gratitude (8) & $72.7 \%$ \\
\hline
\end{tabular}

\begin{tabular}{|c|c|}
\hline Oh (5) & $45.5 \%$ \\
\hline
\end{tabular}

Japanese

\begin{tabular}{|c|c|}
\hline Semantic formulatype & Belongings (17) \\
\hline Gratitude (9) & $52.9 \%$ \\
\hline \multicolumn{2}{|c|}{} \\
\hline A (9) & $52.9 \%$ \\
\hline
\end{tabular}

The English and Japanese groups both commonly used gratitude (72.7\% ad 52.9\% respectively), as well as the discourse markers "a" (52.9\%) and "oh" (45.5\%), when responding to compliments about belongings. Moreover, out of the 9 times in which gratitude occurred in the Japanese belongings responses it was preceded by "a" 7 of those times, and of the 8 times gratitude occurred in the English belongings responses it was preceded by "oh" 5 of those times. The "“a' + gratitude" pattern thus occurred in 7 of the 17 Japanese belongings responses while an "'oh' + gratitude" pattern occurred in 5 of the 11 English responses. The “'a/oh' + gratitude” response pattern appeared to be a rather stereotypic response to compliments about belongings in both language groups. 


\section{CHAPTER 5: DISCUSSION}

\subsection{Research question and hypothesis}

Research Question 1: What response strategies are used by American and Japanese college students when engaging in compliment response in a conversation in a casual setting?

Hypothesis 1: English native speakers will tend to accept more compliments than native Japanese speakers.

$\rightarrow$ Hypothesis 1 is accepted. The English language group accepted $67.5 \%$ of compliments, while the Japanese group accepted $33.3 \%$ of the compliments. (Section 4.1).

Hypothesis 2: Japanese native speakers will tend to avoid and reject more compliments than native English speakers.

$\rightarrow$ Hypothesis 2 is accepted. The Japanese language group avoided $44.9 \%$ and rejected $21.7 \%$ of compliments, while the English group avoided $31.7 \%$ and rejected only $0.8 \%$ of compliments. (Section 4.1 ).

Research Question 2: What similarities and differences are observed between the two groups in the content and sequencing of compliment responses?

Hypothesis 3: When accepting compliments, Japanese native speakers will tend to mitigate acceptance while English native speakers tend to express agreement or gratitude without mitigation. 
$\rightarrow$ Hypothesis 3 is accepted. Of the 57 responses in which the Japanese subjects accepted a compliment $68.4 \%$ were mitigated, while of the 75 responses in which the English subjects accepted only $30.7 \%$ were mitigated. (Section 4.3).

Research Question 3: Does compliment response in each language group vary depending on the topic of the compliment? If so, are there any differences between the two groups in the way the compliment topic relates to compliment response?

Hypothesis 4: Compliment response types will vary according to compliment topic.

$\rightarrow$ Hypothesis 4 is accepted. The study found relations between the content and structure of compliment responses and the type of compliment topic.

Compliment response strategies varied relative to topic, and in a somewhat predictable manner. Acceptance rates were highest for both language groups in responses to compliments about belongings. Responses to compliments about achievements exhibited similarly high acceptance rates. Conversely, avoidance and rejection rates spiked for both language groups in responses to compliments about appearance. Lastly, responses to compliments in the characteristic and ability categories generally fell between the outer extremes of acceptance and rejection ratios in both groups. Some response structures were also unique to a type of compliment topic, including the use of "wa" as a limit on the credit accepted in response to compliments on achievements or the use 
of " 'a' + gratitude" as a means of demonstrating modesty in response to compliments on belongings. (Sections 4.2 and 4.3).

\subsection{Pomerantz's Principle of Self-Praise Avoidance and Leech's Politeness Maxims}

As pointed out in the literature review chapter, Pomerantz (1978) proposed that compliment recipients are confronted with two conflicting preferences. On one hand, there is a preference to (a) avoid self-praise. On the other hand, there is also a preference to (b) agree with the complimenter. These preferences are mutually exclusive in that the avoidance of self-praise necessitates rejection of the compliment and thus disagreement with the complimenter. Conversely, agreeing with the complimenter requires acceptance of the compliment and an implicit ratification of self-praise. Pomerantz concluded that, when engaging in compliment response, complimentees often seek a solution to, or resolution of, this conflict by striking a balance between complete avoidance of self-praise and complete acceptance or agreement.

Leech's (1983) Maxims of Politeness present a similar picture of conflicting preference systems when applied in the context of compliment response. Leech's Modesty Maxim states that a speaker should (a) minimize praise of self [and (b) maximize dispraise of self]. His Agreement Maxim states that a speaker should (a) minimize disagreement between self and other [and (b) maximize agreement between self and other]. These maxims state primary maxims along with weaker submaxims, which are indicated by brackets here. The Agreement and Modesty Maxims come into conflict in the act of compliment response because the complimentee may seek to minimize self-praise by rejecting the compliment, but in the process create disagreement with the 
complimenter, violating the Agreement Maxim. Or, the complimentee may seek to minimize disagreement with the complimenter by accepting the compliment but in the process engage in self-praise, which violates the Modesty Maxim.

Thus when applied to compliment response, Pomerantz's and Leech's constructs operate similarly. The one distinction is that Pomerantz describes a desire to agree with the complimenter, while the Modesty Maxim emphasizes minimization of disagreement. The two constructs will be applied to the findings with respect to the overall results as well as results across the topic categories. Semantic formula data as well as other observed tendencies will support that analysis.

\subsection{Pomerantz and Leech applied to Japanese and English response types}

Leech notes that two maxims may come into conflict with each other, in which case the more "powerful" maxim will take priority over the other. He also notes that the relative strength of maxims will vary between cultures, leading to differing resolutions in situations where maxims conflict. As applied to the language groups in this study, the English group's high rate of acceptance and low rate of rejection is explained by a more “powerful” Agreement Maxim while the Japanese group's tendency to avoid acceptance and rejection of compliments is explained by a compromise between the two.

The English group had a very high acceptance rate (67.5\%) while the group's $0.8 \%$ rejection rate was even more striking. As such, it seems that a very strong Agreement Maxim — a strong tendency to minimize disagreement and maximize agreement between self and other-was operating in the American group examined in this study. The fact that rejection almost never occurred in the data strongly suggests that 
there was a nearly universal aversion to disagreement among the American subjects. And while the acceptance rate was high, the preference to accept was not so dominant as to preclude a relatively high occurrence of avoidance responses (31.7\% of the English group total responses). Thus, it may be inferred that the American subjects sought to both maximize agreement and minimize disagreement but that the preference to minimize disagreement may have been somewhat stronger. Moreover, the desire to avoid disagreement, in alignment with the Agreement Maxim, may have driven the American respondents towards acceptance responses because acceptance provides the surest means of communicating agreement and/or signaling that there is no disagreement.

The influence of the Agreement Maxim was quite apparent in the English group's acceptance responses. The agreement semantic formula occurred in $56.0 \%$ of responses. Example 1 presents a typical acceptance response from the American subjects. Example $1[\mathrm{CR}=$ Compliments response]
[context: compliment stating that it seems the complimentee's friends find him easy to talk to]
CR: oh yeah, I think I'm easy to talk to.

"Yeah" was an extremely common response component in the English group and was often followed by an additional remark as shown here. In this case, the complimentee signaled strong agreement by saying "oh yeah" then essentially repeated the compliment.

In avoidance responses, the English group had a tendency to show agreement or lack of disagreement even when they were rather clearly not accepting the credit attributed by the compliment. Example 2 provides a good example of this response pattern. 


\section{Example 2}

[context: compliment praising the subject for avoiding conflict]

CR: (large nod) It can be a good thing but sometimes I suffer as a result of it ... so I should maybe be a little more ... honest about my feelings. (nodding)

Example 2 reflects a common response pattern in which the subject began the response with a token or limited agreement, followed by what amounted to a contrasting opinion. The first clause, "It can be a good thing," is marked by a very noticeable nod, expressing agreement. The complimentee immediately adds a negative aspect, "I suffer as a result of it," and the need to improve, "I should ... be a little more honest," with the hedges such as 'maybe' and 'a little more' as a means of softening the disagreement.

In the Japanese group the results showed neither extreme acceptance rates nor extreme rejection rates. Rather the proportion of Japanese response types fell within a relatively similar range, with the highest percentage at $46.2 \%$ for Avoidance, followed by $30.6 \%$ for Accept and $23.1 \%$ for Reject. This narrow range of results and high rate of avoidance most likely indicates that neither the desire to avoid self-praise nor the desire to agree with the complimenter was dominant over the other. The Japanese subjects apparently tried to avoid praising themselves, but they similarly shied away from disagreement. Thus avoiding the extremes of acceptance and rejection, the majority of the responses fell into the avoidance category.

A detailed analysis of the semantic formulas used in the acceptance responses by the Japanese group reveals that the responses were often accompanied by statements of mitigation that weakened or counteracted the positive credit that was attributed. A 
strong majority of the Japanese responses were mitigated (68.4\%). This is consistent with the proposition that both self-praise avoidance and the desire to agree with the complimenter factor heavily into Japanese compliment response. While the desire to agree may have prompted the Japanese subjects to accept the compliment, the desire to avoid self-praise prompted them to mitigate the positive content that was attributed.

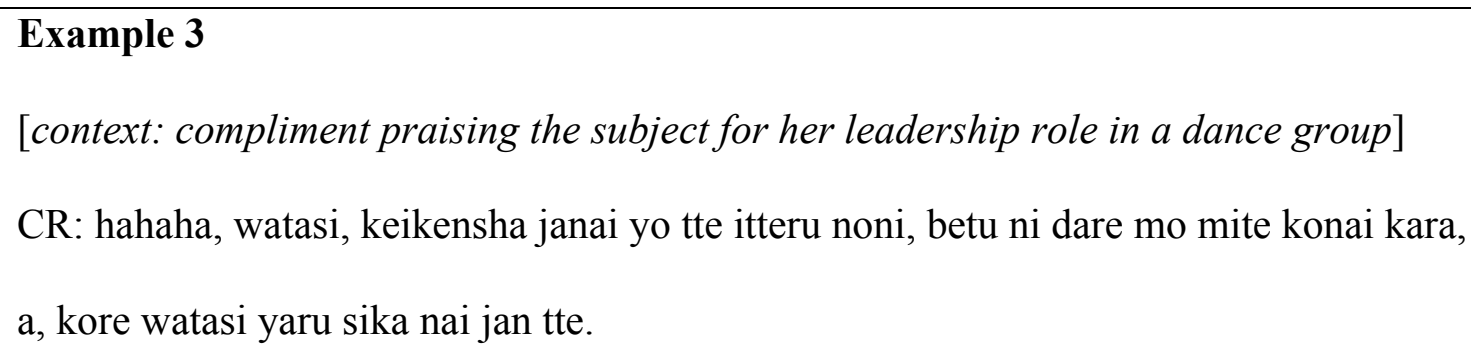

In Example 3, the subject agrees that she took a leadership role, but she does so by downplaying the achievement and casting it in an almost negative light by claiming that she was only put into the role because nobody else would do it. This manner of mitigated acceptance helps to account for the relatively high frequency of acceptance $(30.6 \%)$ found among the Japanese responses.

Another explanation for this relatively high frequency of acceptance is that the use of gratitude allowed the subjects to accept the credit offered in the compliment without expressly agreeing with the content communicated by the compliment. Gratitude was the most common form of acceptance used by Japanese participants (occurring in $43.9 \%$ of Japanese acceptance responses), whereas the use of agreement dominated in the American group. Goffman (1971) states that "giving statements" providing a "ritual offering" tend to be followed immediately by a showing of gratitude, so that the recipient may show appreciation for the offer, affirm the sign of connectedness provided by the 
offer, and to demonstrate their appreciative and grateful nature. Pomerantz (1978) identifies compliments as one such ritual offering and states that appreciation tokens in compliment responses (showings of gratitude) recognize the compliment as an offering without explicitly referencing the content of the compliment. This distinction is significant because, as noted by Holmes (1988), there is a difference between accepting the credit offered by a compliment and accepting/agreeing to the positive attribution communicated by a compliment. The use of gratitude thus allowed Japanese subjects to express appreciation for the act of making the compliment and to avoid disagreement, while also minimizing self-praise by avoiding express agreement with the content of the compliment.

When using gratitude, the Japanese subjects further minimized self-praise through the use of the discourse marker "a." Of the 25 occurrences of gratitude in Japanese acceptance, "a" occurred 17 times. As discussed in Section 4.3, the English discourse marker "oh" and the Japanese discourse "a" were used in very similar circumstances in the data. Schiffrin (1987) states that "oh" in English marks different tasks in the reception of information, including the speaker's receipt of new information. "Oh" is more likely to be used when the locally provided information does not correspond to the speaker's prior expectations and marks a shift in the speaker's orientation to information. Honda (2010) demonstrates that "a" in Japanese and "oh" in English have an equivalent function. Example 4 below demonstrates how "a" and gratitude co-occur in response to a compliment. 


\section{Example 4}

[context: compliment praising the subject's kindness]

$\mathrm{CR}$ : A, arigatoo gozaimasu, hahaha.

In Example 4, "a" recognizes the receipt of the compliment and marks a shift in the recipient's stance by showing that the information is new. In this way, "a" seems to indicate that the compliment, or its content, was unexpected. This function would help the complimentee to avoid self-praise by showing that the complimentee had not previously considered the positive attribution, or that they had not believed such an attribution to be true.

\subsection{Pomerantz and Leech applied to response type results across compliment topic}

Hypothesis 4 proposed that compliment response types would vary according to compliment topic. As shown in Figures 4 and 5, it is clear that the compliment topic categories correspond to a wide continuum of response strategies.

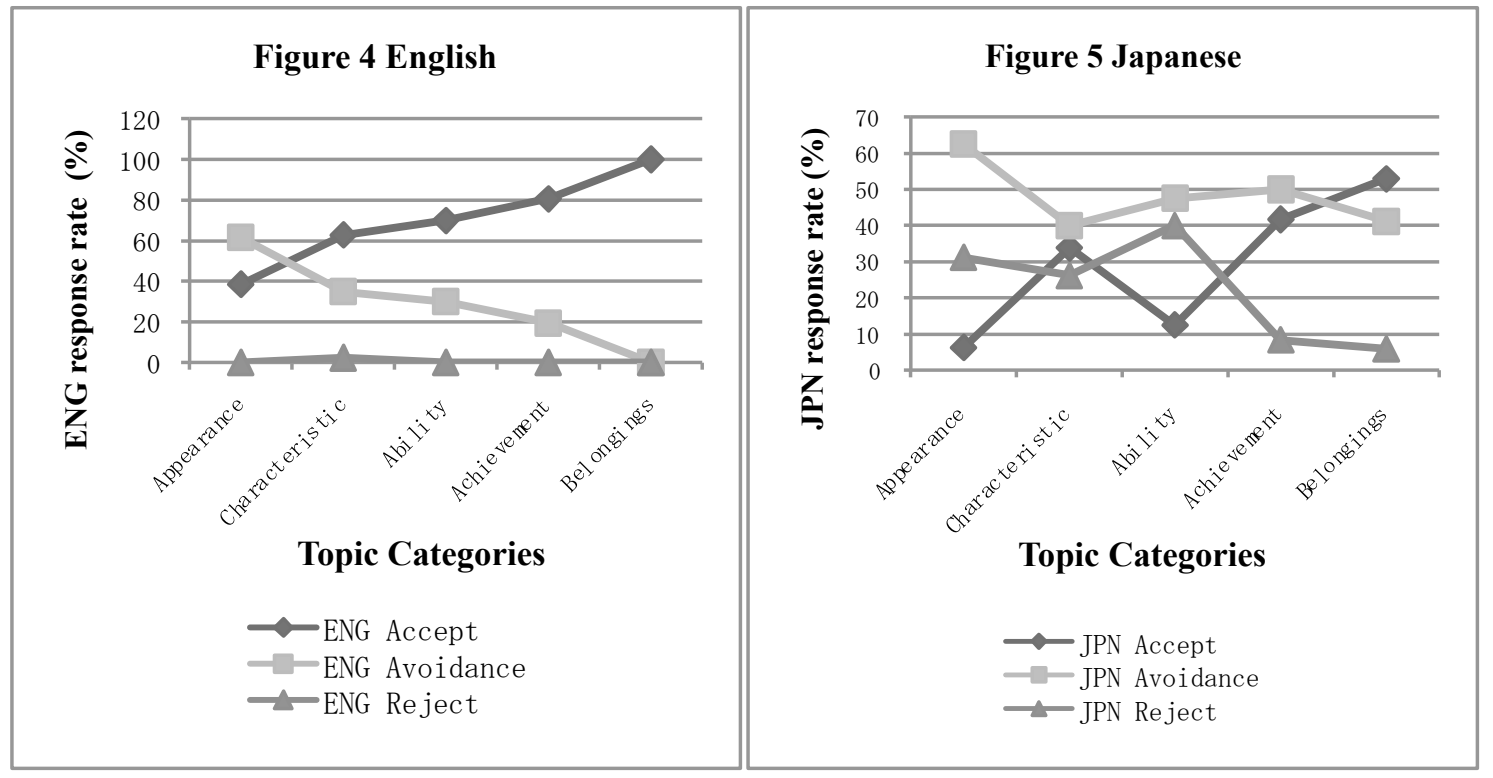


Figure 6 shows how acceptance rates increased or decreased across the compliment topics.

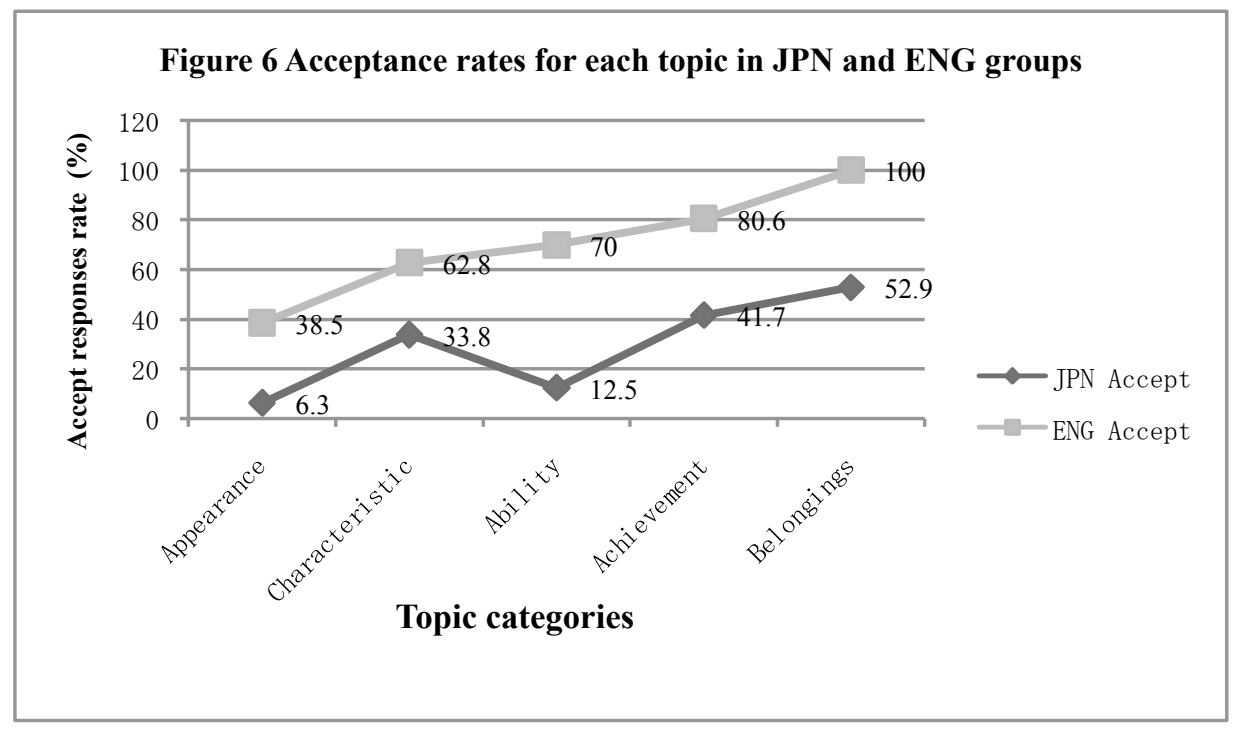

Figure 7 shows the variation in the percentage of rejection responses utilized by the Japanese participants.

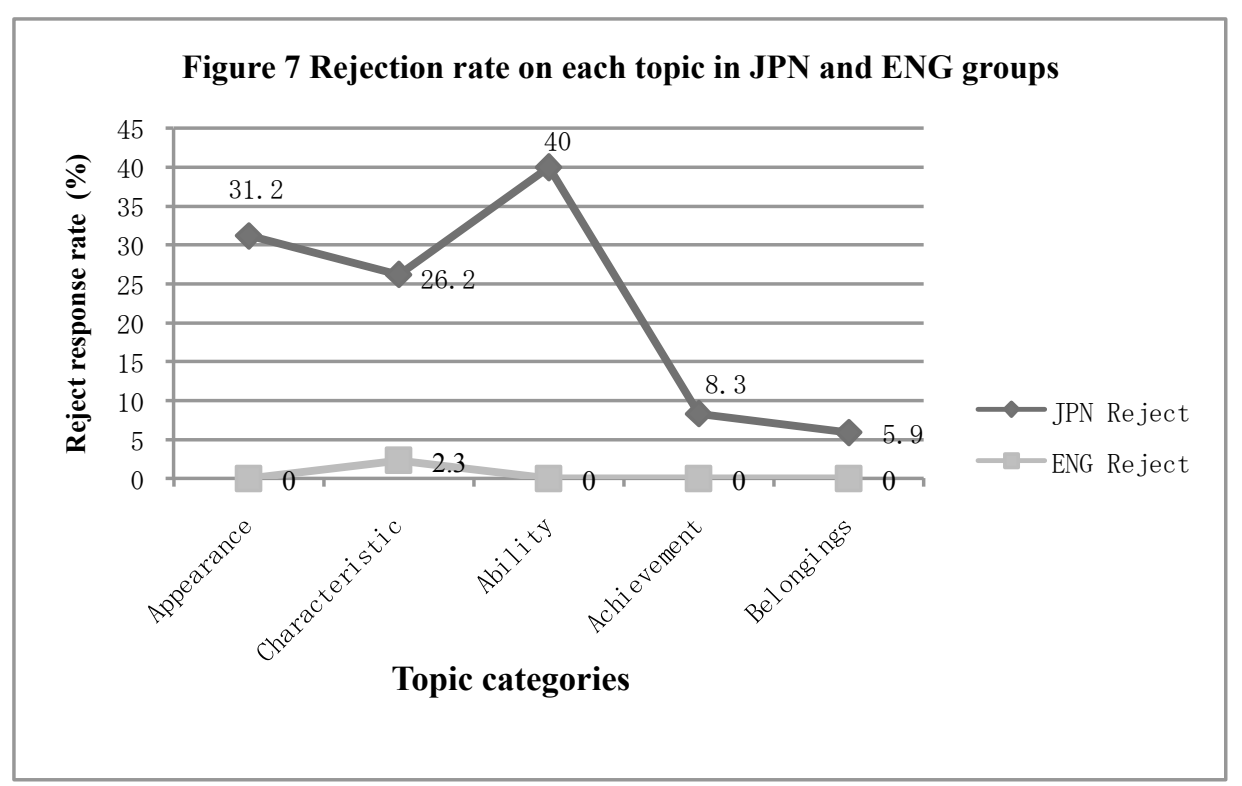


Finally, Figure 8 shows the variation in the percentage of avoidance responses utilized by the English-speaking participants. The Japanese avoidance rate remained fairly stable across all topic categories.

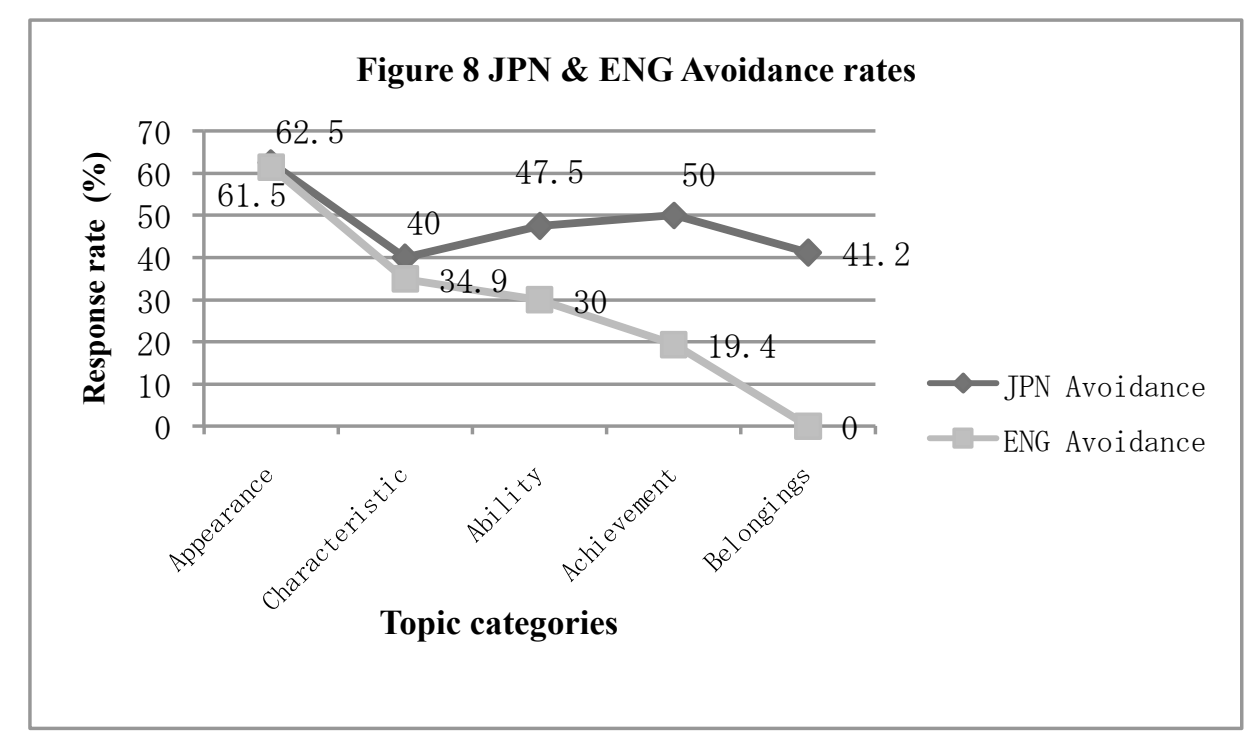

If we accept the principle of self-praise avoidance, the varying response strategies observed in this study can be explained because responses to the target compliment topics carried a greater or lesser risk of self-praise. The consistent variations in the response strategies, as shown in Figures 6,7, and 8, indicates that the risk of self-praise associated with the compliment topics could be placed on an ordered continuum. This continuum would range from those topics associated with the greatest risk of self-praise on one end (i.e. appearance) to those topics associated with a lesser risk of self-praise on the other (i.e. belongings).

Consistent with the trends demonstrated in Figures 6, 7, and 8, the target compliment topics would be presented on such a continuum approximately as follows: [Greatest risk of self-praise] Appearance (face) $\rightarrow$ Personal Characteristic $\rightarrow$ Ability $\rightarrow$ 
Achievement $\rightarrow$ Belongings [Least risk of self-praise]. The direct relationship between compliments about appearance and the complimentee's person supports this conclusion, as acceptance of such compliments assuredly ratifies a positive attribution about the complimentee. Similarly, compliments about belongings bear only an indirect relationship to the complimentee, and acceptance of such compliments ratifies a positive attribution largely directed to the belonging itself.

Previous studies (Baba, 1999 and Fukushima, 1993) have examined differences between compliment responses to compliments about "internal" topics and compliments about "external" topics, however, those studies examined the distinction by grouping compliment topics into either an "internal" or an "external" category. The results from the present study show that even within those categories there were large differences among the responses across compliment topics. For example, "appearance" and "belongings" were categorized as "internal" topics by Baba (1999) but exhibited the largest difference in response percentages observed in this study.

\subsection{Responses in the achievement topic category}

The achievement topic category had a high rate of acceptance in both groups (80.6\% in the English group and $41.7 \%$ in the Japanese group), a low rate of rejection in the Japanese group (8.6\%), and a low rate of avoidance in the English group (19.4\%). This result may be explained by the fact that positive attributions about achievements can be distanced from the complimentee's self and limited to a past event. As occurred in previously discussed topic categories, this limitation on praise attribution may have allowed the Japanese subjects to use the agreement semantic formula more often than 
might have otherwise occurred. While the general trend for the Japanese subjects was to use gratitude in acceptance responses, an unusually high ratio of agreement was used to form accept responses by the Japanese subjects when responding to achievement compliments $(66.7 \%)$.

What is notable about the Japanese agreement responses to compliments on achievement is the use of the qualifying particle $w a$ in order to limit the applicability of the agreed upon positive attribution. As will be discussed below, this usage of wa is illustrative of the importance of the distance between the compliment referent and the complimentee, as well as of the ways in which that distance can be manipulated by the complimentee to minimize self-praise.

\section{6 "Wa" + [agreement]}

The phrase particle wa establishes the preceding " $\mathrm{X}$ " as the limit of applicability; that " $\mathrm{X}$ " is the speaker's only referent of the moment, the only item for which he or she takes current responsibility (Jorden \& Noda, 1987). Through the use of $w a$, the Japanese subjects agreed with compliments but in a manner that limited the complimented referent to an event that had happened in the past.

In Example 5, the subject acknowledges that at the time she was studying for her school entrance exam, she may have been working hard, however the use of wa establishes that her acknowledgement that she was working hard applies specifically to that time period before her entrance exam, leaving other time periods ambiguous. 


\section{Example 5}

[context: compliment regarding the subject's effort in studying for her university entrance exam]

CR: ima wa moo mata asa nigate ni modocchatta n desu kedo, sono koro wa chanto okite...

She explicitly contrasts that past period of hard work, "sono koro wa," with her present habits, "ima wa," saying that she is now bad at waking up early. She also uses "mata (again)" to imply that she had been a kind of a person who was not good at waking up early, a state to which she reverted after the entrance exam period. By using mata in combination with $w a$, she states she is now bad at waking up, that she was bad at waking up previously, and that the only exception (to this bad trait that she attributes to herself) is the exclusive period when she was studying for her entrance exam. Thus, she accepts the compliment, and even agrees with it, but she does so in a manner that entirely limits the positive attribution to a limited period in the past, while at the same time attributing a contrasting negative trait to herself for all other time periods.

The limiting function of wa may have also allowed the Japanese participants to engage in response patterns that were otherwise dispreferred, or atypical.

\section{Example 6}

[context: compliment regarding the subject's effort in studying for his university entrance exam]

CR: erakatta desu yo, hontoo ni, sono koro wa tte iu, hahaha...

In Example 6, the subject similarly agrees to a compliment regarding his hard work in preparing for his university entrance exam. But, in an extremely rare occurrence for the Japanese group, he actually upgrades the compliment using "erakatta desu yo, hontoo $n i$ 
(It is admirable, really)." This response represented only 1 of 2 upgrade formulas used in the entire Japanese corpus of data (1.1\% of responses). However, through the use of wa the force of the upgrade is explicitly limited only to the specific period of time before his entrance exam. He states that at that time he really did do well and worked hard, but the use of wa precludes the implication that the statement still applies. He is thus able to distance himself temporally from the referent receiving the positive attribution. It is also interesting that the subject uses an inverted sentence structure, adding "sono koro wa" after upgrading, perhaps to emphasize the limitation on the upgrading statement.

Japanese subjects also used $w a$ to not only limit the temporal referent of agreement but also to characterize the self as a third-person that existed in the far distant past as in Example 7.

\section{Example 7}

[context: compliment regarding the subject's effort in training for his high school baseball team ]

CR: sono toki no ore wa ganbatteta kana, haha...

In Example 7 the subject refers to himself in the third person as "sono toki no ore," which literally translates to "that time me" or "the me of that time." That phrase precedes wa, meaning that the following predicate "ganbattetta" applies exclusively to "sono toki no ore," or "the me of that time." $W a$ functions to again limit the time referent to the period in which his effort occurred, but here it also means, in a literal sense, that the referent is limited to the version of himself that existed at that time. In this way, the subject communicates agreement with the compliment but at the same time implies that the past self to whom praise is being attributed is somehow distinct from who he is now. Thus, the 
subject was able to at least imply that even if he was once a person worthy of praise, he has changed and is unworthy of such praise in the present.

When corresponding to a change in intonation, the use of $w a$ can also indicate limited applicability of the predicate to the item that precedes $w a$ (Jorden and Noda, 1987). Example 8 below demonstrates how this usage of $w a$ also occurred in the data in order to limit the amount of praise accepted.

\section{Example 8}

[context: compliment regarding the subject's effort in studying for his university entrance exam]

CR: Juken WA ganbarimasita

In Example 8 the subject agrees that he did work hard in preparing for his university entrance exam. However, the use of focus-intonation contrasts that one event with other unnamed events. The overall message communicated is that he did, at least, work hard in connection with his entrance exam but that he is not so sure about his work in connection with anything else. Much like Example 1, the effect is to agree with the compliment, but to limit that agreement to a discrete event while simultaneously implying that he is in most other respects not hard working at all.

Finally, some other expressions of limitation, such as dake (only) or yuitu (the only; solitary) were also observed in the achievement category.

\section{Example 9}

[context: compliment regarding the subject's dedication to her high school badminton club]

CR: Yuiitu ganbatta koto kana. 
Yuiitu here functions similarly to the way wa has been used above, but it communicates the limitation on agreement more directly. $\mathrm{Wa}$ limits agreement by indicating that it applies only to the particular referent and nothing else, but it does not insist that the referent is the exhaustive list of all referents deserving the positive attribution. Yuiitu and dake do, however, make a claim with respect to non-listed referents. They state that the particular referent is the only one worthy of such praise, no more no less. In effect $w a$ states "I am agreeing to the praise with respect to $\mathrm{X}$ but make no claim with respect to anything else," while yuiitu and dake state "I agree to the praise with respect to X but will not accept praise with respect to anything else."

The use of the linguistic devices that express limited applicability enabled the Japanese participants to mitigate the agreement with compliments without relying on the conventional mitigating semantic formulas. These linguistic devices limit the extent to which the compliments reflected on the current self by associating the praise-worthy characteristic or achievement with a former time period or the past self. These patterns were not found in the English group. 


\section{CHAPTER 6:}

CONCLUSION

The goal of this study, when stated in general terms, was to examine the response strategies used by American and Japanese college students when engaging in compliment response in a casual conversation. More specifically, the study asked whether compliment responses in each language group vary depending on the topic of the compliment and, if so, whether there are any differences between the two groups in the way the compliment topic relates to compliment response.

The overall results indicated that English native speakers tend to accept more compliments than native Japanese speakers and that Japanese native speakers will tend to avoid and reject more compliments than native English speakers. The English language group accepted $67.5 \%$ of compliments, while the Japanese group accepted $33.3 \%$ of the compliments. Meanwhile, the Japanese language group avoided $44.9 \%$ and rejected $21.7 \%$ of compliments, while the English group avoided $31.7 \%$ and rejected just $0.8 \%$ of compliments.

These results corroborated the principles of Leech's Agreement and Modesty Maxims and Pomerantz's analysis of the conflicting constraints of self-praise avoidance and the desire to agree with the complimenter. Due to the English group's extremely low rejection rate and relatively high acceptance rate, it was determined that the Agreement Maxim was the dominant force in their responses. The Japanese group's responses, by contrast, depicted a more even balance of the forces described in Pomerantz's model of 
conflicting constraints, as neither the Agreement nor the Modesty Maxim appeared to be dominant over the other.

This study also examined some qualitative differences in the ways in which the Japanese and American subjects commonly engaged in compliment response. Most notably, when accepting compliments, Japanese native speakers tended to mitigate acceptance while English native speakers tended to express agreement or gratitude without mitigation. Of the 57 responses in which the Japanese subjects accepted the compliment $68.4 \%$ were mitigated, while of the 75 responses in which the English subjects accepted compliments, only $30.7 \%$ were mitigated.

Finally, the findings showed a definite progressive relationship between changes in compliment topic and variations in compliment response ratios. This result demonstrates that consideration of compliment topic is necessary when undertaking a study of compliment response. Differences in response ratios across topic were both substantial and fairly predictable. This finding makes it quite clear that studies that fail to account for compliment topic may produce variation in their data which could have potentially been avoided.

Limitations of this study

Lastly, this study has its limitations. Due to insufficient sample size and nonrandom subject selection, the study was not able to make conclusions across the entire population of American English speakers and native Japanese speakers. Moreover, the research design of this study aimed to gather naturally occurring data in a casual setting, but it also sought to allow for a systematic analysis of variations in compliment response 
across compliment topics. As a result, certain compromises between authenticity and repeatability had to be made. The major compromise was the use of the researcher and research assistant as complimenters. While this use provided assurance that nearly all the target compliment topic categories were covered in every conversation, it may have affected the number and sequence of compliments given and produced a slightly stilted type of social interaction. Steps were taken to present the researcher and researcher assistant as students, rather than researchers, but it is possible that some of the subjects may have perceived the setting as somewhat unnatural because of the recording device, the pre-conversation survey, and the consent form.

In spite of these limitations, the study is deemed to have been successful in eliciting data that enabled the researcher to compare the Japanese and English groups in terms of compliment response as well as to examine the relationships between the topic categories and response types. 


\section{REFERENCES}

Baba, J. (1999). Interlanguage pragmatics: Compliment responses by learners of Japanese and English as a second language. Newcastle: LIMCOM Europa.

Bardovi-Harlig, K. (2001). Evaluating the empirical evidence: Grounds for instruction?

In Rose, K. \& Kasper, G. (Eds.), Pragmatics in language teaching (pp. 13-32). New York: Cambridge University Press.

Bardovi-Harlig, K. (2006). On the role of formulas in the acquisition of L2 pragmatics. In Bardovi-Harlig, K. et al. (Eds.), Pragmatics language learning (pp. 1-28). Manoa, Hawaii: University of Hawaii Press.

Brown, P \& Levinson, S. (1987). Universals in language usage: Politeness phenomena. Cambridge: Cambridge University Press.

Chen, R \& Yang, D. (2010). Responding to compliments in Chinese: Has it changed? Journal of Pragmatics. 42, pp. 1951-1963.

Daikuhara, M. (1986). A study of compliments from a cross-cultural perspective: Japanese vs. American English. WPEL: Working Papers in Educational Linguistics. 2:2, pp. 103-134.

Fukushima, N. (1990). A study of Japanese communication: compliment-rejection, production and second language instruction. Dissertation. University of Southern California, Los Angeles.

Golato, A. (2003). Studying compliment responses: A comparison of DCTs and recordings of naturally occurring talk. Applied Linguistics, 24:1, pp. 90-121. 
Holmes, J. (1986). Compliments and compliment responses in New Zealand English. Anthropological Linguistics, 28:4, pp. 485-508

Markus, H \& Kitayama, S. (1991). Culture and self: implications for cognition, emotion, and motivation. Psychological Review, 98:2, pp. 224-253.

Pomerantz, A. (1978). Compliment responses: Notes on the cooperation of multiple constraints. Studies in the organization of conversational interaction (pp. 79-112). New York: Academic Press.

Saito \& Beecken (1997). An approach to instruction of pragmatic aspects: Implications of pragmatic transfer by American learners of Japanese. The Modern Language Journal, 81:3, pp. 363-377.

Schiffrin, D. (1987). Discourse Markers. New York: Cambridge University Press.

Searle, J. R. (1975). A taxonomy of illocutionary acts. In Günderson, K. (Ed.), Language, Mind, and Knowledge, Minneapolis (Vol. 7).

Searle, J. R. (1979). Expression and meaning: Studies in the theory of speech acts. New York: Cambridge University Press.

Shimizu, T. (2009). "Influence of learning context on L2 pragmatic realization: A comparison between JSL and JFL learners' compliment responses.” In Taguchi, N. (Ed.), Pragmatic Competence (pp. 167-198). New York: Mouton de Gruyter.

Takahashi, T. \& Bebe, L. M. (1993). Cross-linguistic influence in the speech act of correction.” In Kasper, G. \& Blum-Kulka, S. (Eds.) Interlanguage Pragmatics. New York: Oxford University Press. 
Wolfson, N. (1981). Compliments in cross-cultural perspective. TESOL Quarterly, 15:2, pp. 117-124.

Yokota, J. (1985). Homerareta toki no hentoo ni okeru bokokugo kara no shakai gengogakuteki teni. [Sociolinguistic transfer from the native language in the response to compliments]. Journal of Japanese Language Teaching, 58, pp. 203-223. 


\title{
APPENDIX A: ENGLISH INFORMED CONSENT FORM
}

\author{
Research Project: Semantic Formula Analysis of communicative behaviors \\ of native speakers of Japanese and English
}

You are invited to participate in a research study conducted by Hiroko Katsuta from Portland State University, the Department of World Language and Literature at Portland State University. The researcher hopes to compare what strategies, techniques, and structures native speakers of Japanese and native speakers of English use in face-to-face interaction. In particular, the researcher hopes that through this comparison it will be possible to identify some tendencies in the communicative strategies of English and Japanese speakers. The study is being conducted in partial fulfillment of the requirements for a master's degree and is conducted under the supervision of Professor Suwako Watanabe. You were selected as a possible participant in this study because you are a native speaker of either Japanese or English.

\section{What will you be asked to do?}

If you decide to participate, you will be asked to fill out a survey and participate in a follow-up interview, which will include a short multiple-choice quiz. The interview will be video-recorded. The estimated length of time for the interview is from 10 minutes to 30 minutes. We can have the interview at a time convenient for you and at any place where you feel comfortable as long as our interview can be recorded properly. This is not a test, so you can pause or stop the interview at any time.

\section{How will the recordings be used?}

Your interview along with other people's interviews will be used for research purposes. For research, I will transcribe selected responses to the interview situations and find linguistic patterns that characterize the strategies, styles, and structures that you used in your responses and compare your responses with those of other participants. I will also identify trends in the responses from the two groups of participants (native Japanese, native English,) and compare the two groups to each other.

When I transcribe the responses from the recordings, I will remove or change all the information that may lead to your identification. When I report the results of the study, some of the findings will be presented as a group. In some cases, I will include transcribed excerpts (examples) from the recordings. It is very unlikely that the audience of those findings will identify you, but you can always tell me not to use your interview even after the interview is done.

\section{What risks are involved in this study?}

One of the risks may be the amount of the time required. I will set up a time that is convenient for you. You can stop the interview at any time.

For some people, having oneself and his/her speech video- and audio-recorded is very uncomfortable. Some people may be concerned that they may make mistakes. This is not a test, so making mistakes does not matter and you can take as long time as you want to respond. It is important that you take part in the interview as naturally as possible. You can stop the interview or withdraw from the study at any time, even after the interview is done. If you withdraw there will be no penalty.

The information you give me will be kept confidential to the extent permitted by law. Copies of the recordings, the transcriptions, and the consent forms will be kept in a secure locker 
in my house or in secure folders on my personal computer. When I report findings of the study, I will use pseudonyms for any personal names but some general demographic information such as gender and approximate age will not be changed.

You may not receive any direct benefit from taking part in this study, but the study may help to increase knowledge which may help others in the future.

Your participation is voluntary.

Your participation is voluntary. You do not have to take part in this study, and whether you participate or not will not affect your course grade or relationship with Portland State University or me. You may also withdraw from this study at any time without any penalty.

If you have concerns or problems about your participation in this study or your rights as a research project, please contact the Human Research Review Committee, Research and Strategic Partnerships, Market Center Building, Suite 620, 1600 SW Fourth Ave., Portland, OR 97207.

If you have questions about the study itself, contact Hiroko Katsuta, Dept. of World Language and Literature, P.O. Box 751, Portland, OR 97207-0751, (503)867-9007, email: k.hiroko1203@gmail.com.

Your signature indicates that you have read and understand the above information and agree to take part in this study.

Please understand that you may withdraw your consent at any time without penalty, and that by signing, you are not waiving any legal claims, rights, or remedies. The researcher will provide you with a copy of this form for your own records.

Signature

Date

Name (please print) 


\title{
APPENDIX B: JAPANESE INFORMED CONSENT FORM
}

\author{
アメリカ人英語母語話者と日本人の日本語母語話者による叙述方法の比較研究における同意書
} (日本人の日本語母語話者の方用)

今回このリサーチでは、アメリカ人英語母語話者と日本人の日本語母語話者による叙述方法の比較を目的 としています。アメリカ人英語話者と日本人日本語話者の叙述法を比較することにより、それぞれの言語間 にどのような傾向が見られるかを考察するというものです。このリサーチ結果は研究者の修士論文のための 研究データとして使用されることになります。今回このリサーチにご参加頂く参加者の方は、日本語母語話 者としての被験者という立場になります。

データ収集内容：今回、このリサーチの被験者になって頂く方には、まずアンケートに答えて頂き、その 後インタビューに参加して頂く事になります。インタビューは録音記録されます。インタビューは約 20 分 程度です。インタビューの途中であっても、録音を止めたい場合はいつでも中断して頂けます。これはテス トではありませんので、いつでも自由な時にインタビューを止めることができます。

データ管理：このインタビューは他の被験者のデータと共に研究目的にのみ使用されます。分析段階とし て、インタビューの会話内容は文字化され、さらに詳細を分析する事になります。ただし、個人を特定でき る内容は全て取り除かれ、このデータから個人が特定できる事はありません。分析の結果は、個人ではなく それぞれの言語グループに分けられるので、この結果から個人が特定されることもありません。

実験におけるリスク：想定されるリスクとしては、時間拘束、緊張が考えられますが、インタビューは途 中であっても止める事ができます。インタビューを中断しても被験者にペナルティーが課されることはあり ません。検出データは安全な場所に保管され、コピーや録音されたものが外部に持ち出される事はありませ ん。また、この研究において、実際の個人の名前や年齢などが表記されることはありません。

参加意志 : このリサーチへの参加はボランティアですので、参加の有無によって研究者との関係、または 被験者への学業面での影響があることはありません。

このリサーチに関して、または被験者の権利に関して質問等がある場合は以下の連絡先に連絡してくださ い。

Human Research Review Committee, Research and Strategic Partnerships, Market Center Building, Suite 620, 1600 SW Fourth Ave., Portland, OR 97207.

研究者に対しての質問等は以下に連絡をお願い致します。

Hiroko Katsuta, Dept. of World Language and Literature, P.O. Box 751, Portland, OR 97207-0751, (503)867-9007, email: k.hiroko1203@gmail.com.

下記に署名をして頂く事により、このリサーチへの参加の意志が表明されますので、上記をお読みになり 承認して頂く際のみ署名をお願い致します。

ご署名

日付

お名前 


\section{APPENDIX C: \\ ENGLISH BIOGRAPHIC INFORMATION QUESTIONNAIRE}

1. Name:

2. Gender (Please circle one): M / F

3. Age:

4. What is your native spoken language? (Please circle one): Japanese / English

5. (For native Japanese speakers) What is your length of stay in the U.S.? 


\section{APPENDIX D:}

JAPANESE BIOGRAPHIC INFORMATION QUESTIONNAIRE

名前：

年齢：

性別：

母国語：

アメリカでの滞在期間 : 


\section{APPENDIX E: \\ ENGLISH PRE-CONVERSATION SURVEY}

\section{$<$ Questionnaires $>$}

INSTRUCTIONS: The information you provide in this survey will form the basis for topics of discussion in the conversation session. Your conversation with the researcher/research assistant at the interview will provide data to be used in a linguistic analysis. That analysis will examine the form, structure, and general content of your responses. The analysis will not judge or examine, in any way, anything with respect to the quality of your responses. Any information you provide in this survey or in the interview that identifies you as the participant will be deleted from the record and will not be used in any papers or publications.

We understand that it may be difficult to answer some of these questions, but we would really appreciate it if you could do your best to answer them as fully as you can. Thank you so much for your help!

1. Please describe the positive and negative points of your personality.

2. Please describe one of your achievements.

3. Please briefly describe something you feel you can do really well. 


\section{APPENDIX F: \\ JAPANESE PRE-CONVERSATION SURVEY}

く事前アンケート >

このリサーチは、言語学的なリサーチ目的ですので、返答の内容や個人の考えなどについて判断 するものではありません。お答え頂く内容は、リサーチ目的以外に使われる事はありません。

質問の中には、答えるのが難しいと感じるものもあるかもしれませんが、なるべく一つの質問に 対して一つは答えを書いて頂くようお願い致します。ご協力ありがとうございます。

1.あなたの長所と短所は?

2.あなたが得意なこと、または特技は？（skill/ability）

3. 今までで自分でがんばったと思うこと、または達成したことは？ 


\section{APPENDIX G: CONVERSATION PLAN}

1. Greeting.

2. $\rightarrow$ Compliment on their clothes or belongings (bag, phone, etc.) (I really like your ...)

3. Ask them to fill out the Biographical Information Questionnaire and the short grammar quiz.

4. $\rightarrow$ Make a compliment on their quiz performance. (Wow, you are good at grammar!)

5. Quick small talk (how are you, are you nervous? etc.)

6. Pretend you have to check the camera position. $\rightarrow$ Compliment their face. (You have such a [cute / pretty / kind / etc.] face.

7. Discuss their response to Question 1 (discuss different topics related to it, ask them to expand on their answer ... if the conversation moves on to different related topics that is fine too!)

$\rightarrow$ Compliment something their personality at some point in this discussion (It seems to me that you are ...)

- With this compliment, upgrade a positive point mentioned in the questionnaire. For example, if the questionnaire says something like "I am a nice person and care for others," that can be upgraded to "It seems to me that you are a compassionate person."

8. Discuss their response to Question 2.

$\rightarrow$ Compliment something related their achievement. "I think it is really [impressive] that you were able to ..." or "I think what you did was [courageous / clever / etc.]"

9. Discuss their response to Question 3.

$\rightarrow$ Compliment something related to their ability. "That is really impressive, I definitely can't do that." or "I wish I could do that."

10. Discuss what the volunteer partner said for Question 4. "... said that you are ..."

11. Thank them for coming! 